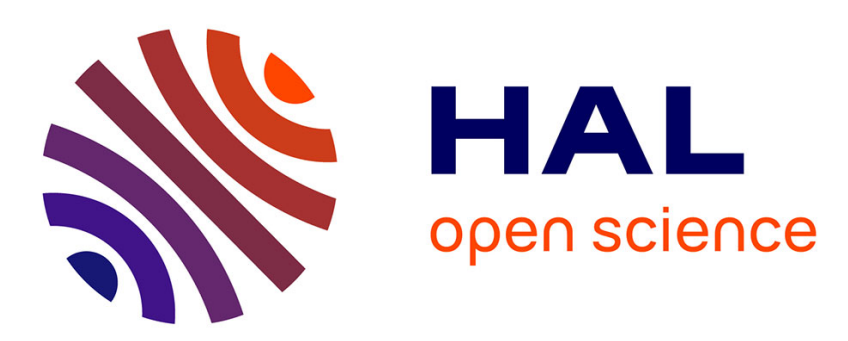

\title{
Natural bond orbital approach to the transmission of substituent effect through the fulvene and benzene ring systems
}

\author{
Wojciech P. Oziminski, Tadeusz M. Krygowski
}

\section{- To cite this version:}

Wojciech P. Oziminski, Tadeusz M. Krygowski. Natural bond orbital approach to the transmission of substituent effect through the fulvene and benzene ring systems. Journal of Molecular Modeling, 2010, 17 (3), pp.565-572. 10.1007/s00894-010-0753-1 . hal-00596733

\section{HAL Id: hal-00596733 \\ https://hal.science/hal-00596733}

Submitted on 30 May 2011

HAL is a multi-disciplinary open access archive for the deposit and dissemination of scientific research documents, whether they are published or not. The documents may come from teaching and research institutions in France or abroad, or from public or private research centers.
L'archive ouverte pluridisciplinaire HAL, est destinée au dépôt et à la diffusion de documents scientifiques de niveau recherche, publiés ou non, émanant des établissements d'enseignement et de recherche français ou étrangers, des laboratoires publics ou privés. 


\section{Editorial Manager(tm) for Journal of Molecular Modeling Manuscript Draft}

\section{Manuscript Number: JMM01300R1}

Title: Natural Bond Orbital approach to the transmission of substituent effect through the fulvene and benzene ring systems

Article Type: Original paper

Keywords: NBO; DFT; fulvene; substituent effect; pEDA

Corresponding Author: Dr Wojciech Piotr Oziminski, Ph.D.

Corresponding Author's Institution: National Medicines Institute

First Author: Wojciech P Oziminski, Ph.D.

Order of Authors: Wojciech P Oziminski, Ph.D.; Tadeusz M Krygowski, Professor

Abstract: Electronic structure of 22 monosubstituted derivatives of benzene and exocyclically substituted fulvene with substituents: $\mathrm{B}(\mathrm{OH}) 2, \mathrm{BH} 2, \mathrm{CCH}, \mathrm{CF} 3, \mathrm{CH} 3, \mathrm{CHCH} 2, \mathrm{CHO}, \mathrm{Cl}, \mathrm{CMe} 3, \mathrm{CN}, \mathrm{COCH} 3$, $\mathrm{CONH} 2, \mathrm{COOH}, \mathrm{F}, \mathrm{NH} 2, \mathrm{NMe} 2, \mathrm{NO}, \mathrm{NO} 2, \mathrm{OCH} 3, \mathrm{OH}, \mathrm{SiH} 3, \mathrm{SiMe} 3$ were studied theoretically by means of Natural Bond Orbital analysis. It is shown, that sum of -electron population of carbon atoms of the fulvene and benzene rings, $\mathrm{pEDA}(\mathrm{F})$ and $\mathrm{pEDA}(\mathrm{B})$, respectively correlate well with Hammett substituent constants ? $\mathrm{p}+$ and aromaticity index NICS. The substituent effect acting on pielectron occupation at carbon atoms of the fulvene ring is significantly stronger than in the case of benzene. Electron occupations of ring carbon atoms (except C1) in fulvene plotted against each other give linear regressions with high correlation coefficients. The same is true for ortho- and para- carbon atoms in benzene. Positive slopes of the regressions indicate similar for fulvene and benzene kind of substituent effect - mostly resonance in nature. Only the regressions of occupation at carbon atom in metaposition of benzene against ortho- and para- positions gives negative slopes and low correlation coefficients.

Response to Reviewers:

Reviewer \#1:

The manuscript attempts to reveal dependencies of the pi-electron populations in fulvene and benzene on various substituents. The results show linear relationships and significant difference between fulvene and benzene.

This was our purpose to present a difference between monosubstituted benzene and exocyclically but also monosubstituted fulvene: comparison of the substituent effect operating in the non-alternent and alternant hydrocarbons.

However, the manuscript is organized and written poorly.

This is a general statement which does not help in any improvement of the MS. The idea of the MS was firstly to present general response of the fulvene ring on action of the substituents in comparison with benzene ring, and then the relations with aromaticity (via Schleyer's NICS) This is shown in Figs $4,5,6,7,6$. Secondly, there are presented dependences of $2 p$ occupation at carbon atoms in particular positions in fulvene on substituent constants (Fig. 9,10,11.) Thirdly, a direct comparison of $2 p$ occupations at appropriate positions in benzene and fulvene (Fig. 12,13,14). Then, it is shown that $2 p$ 
occupations in a similar pairs of carbon atoms (ortho- and para- positions in benzene and 1- and averaged 3-,4- positions in fulvene are correlated, whereas it is not the case for ortho/meta pair in benzene (Fig. 17) and this is clearly resulting from scheme of resonance in Fig.3. Finally, it was shown(Fig. 18) that aromaticity of the ring changes collinearly with substituent constants only for electron donating substituents, whereas for others there is no correlation. The conclusions at the end summarize these results. In principle, most important information results directly from figures, but despite of this fact, there is an explanation in the text.

For instance, the introduction is not to-the-point on the purpose of this research.

Now we included some additional references, mostly for di-substituted aromatics, in which communication between substituents (one of them being fixed in a series and "working" as reaction or process site). We have also added some more explanation for using the term transmission.

The background and previous researches are lacking.

Reply: This is now done. For non-alternant hydrocarbons there are not known any systematic works on transmission of the substituent effect in a classical meaning i.e. as a meaure of interactions between two substituents attached to the same molecular moiety. We intend to continue work in this direction but first step must be done first.

The description of the di-substituted species seems unnecessary.

Reply: There are no data for di-substituted species presented in the MS.

The choice of the substituents is not explained.

Reply: Of 22 substituents that are considered in the MS substituents with all kinds of typical interactions known for substituent effects are taken into account, cf. two examples: strongly electron donating by resonance e.g. $\mathrm{OMe}(\sigma \mathrm{R}=-0.63)$; with a substantial contribution of (electron accepting) inductive effects $(\sigma \mathrm{I}=0.31)$, or strongly electron donating by resonance $\mathrm{NMe} 2,(\sigma \mathrm{R}=-0.94)$ with a moderate(electron accepting) inductive effects; $(\sigma \mathrm{I}=0.11)$, then also strongly electron accepting by resonance with a strong inductive effect (also accepting)e.g. NO2 $(\sigma \mathrm{I}=0.70)$ and strongly electron accepting by resonance $(\sigma \mathrm{R}-=0.40)$ [numerical data from: O.Exner, The Hammett Equation, chpt. 1 in Adv. In LFER, ed. N. Chapman and J. Shorter, Plenum Press 1972]. In this way 22 substituents ensure a variety of kinds of substituent effects, sufficient for getting reliable conclusions.

The description of results and discussion are unclear and insufficient.

Reply: This is a general statement which does not help in any improvement of the MS.

Where are the substituent constants from? 0.269/0.184 seem not matching with the figures. Reply: The referee is right, we did not made reference, now it is done. The data were taken from[ Hansch, C.; Leo, A.; Taft, R. W. Chem. Rev. 1991, 91, 165] and the ratio of ranges for $\sigma p / \sigma m$ was done for all 223 substituents in Table $\mathrm{V}$ in the Taft review. That is why there is a disagreement observed by the Referee:.

What is cc and what does "ortho-benzene" mean in the plots? etc. Reply: cc means correlation coefficient. Now it is explained. In figures:12, 13, 14, 15 and 17 ortho-, meta-, para- mean carbon atoms in benzene ring in positions ortho-, meta- and para-

All these prevents a thorough review to be made. The manuscript in the current form is not appropriate for publication. 
Reply: We hope that after revision made and replies to the criticism of the Referee our MS may be accepted for publication.

\section{Reviewer \#2}

The manuscript by Oziminski and Krygowski is quite interesting and suitable for JMM. It provides a theoretical insight in the electronic structure of fulvene and benzene, and their D/A mono-substituted derivatives. The authors use a quite reliable approach (DFT) and find out interesting properties to be compared. However, there are some comments and questions that should be addressed by authors before publishing.

The comments are as follows:

1) The abstract contains too many details about methods and software used. That can be omitted there without loss in sense. Instead, it would be worth explaining some other details. For instance, it is unknown (without reading the article) what slopes are mentioned. The sentence starting from "Occupations in all positions..." seems confusing. What could it be "an occupation in a position"? The sense of the sentence erroneously looks like "Occupations ... are ... correlated with positive slopes..." The last sentence is not quite clear either. There are some abbreviations and notations that seem redundant in the abstract.

Reply: According to Reviewer suggestions the abstract is now completely rewritten.

2) The authors set a question in the introduction: how the pi-electron structure looks like. However, a direct answer does not seem to be given in the paper.

Reply: We believe that we answered the question stated in the introduction. We described the pielectron structure of the fulvene and benzene rings by analysing electron occupations of ring carbon atoms, their interrelationships and relations to classical resonance structures.

3) In the Results and discussion section it is said that Figs 2 and 3 present "the canonical structures". Meanwhile the figure captures state "Resonance structures". What are they and why do they (Fig. 2) contain one implicit H-atom less than the structure in Fig. 1? The authors mention also some "resonant interactions" in the sentence above Fig. 17.

Reply: By canonical and resonance structures we mean the sam - they can be also called "canonical resonance structures". By the names should be the same for figures and text so we changed it now in all places to "resonance structures". The structures in Fig. 1 and 2 contain the same number of hydrogen atoms. The difference is only in that the structures in Fig. 2 describe charge shifts from substituent to the fulvene ring. Thus, for electron donating substituents (like NH2 group) the charge is shifted from $\mathrm{NH} 2$ to one of the fulvene ring carbon atoms and this atom consequently has point negative charge and single bond to his neighbours. Resonance structures are a classical concept of organic chemistry recently quantitatively described by Natural Resonance Theory by Weinhold and coworkers.

By the sentence above figure 17 by the lack of possibility of "resonance interactions" we mean that there is no possibility to construct a resonance structure for benzene where the charge is positioned at the meta- position. 
4) The first aspect just under the Fig. 3 capture mentions "these differences". What differences are meant?

Reply: We mean the differences in substituent effect transmission for benzene and fulvene. The Referee is right that we should be more specific. Now this sentence reads: "how differences in substituent effect transmission through benzene and fulvene affect the overall electron structure of benzene and fulvene rings"

5) A definition for sigma_p+ is given in the abstract. It should be defined in the text.

Reply: The sigma_p+ constant is defined similarly to classical Hammett substituent constant but it relates to interactons with positively charged "reaction site". Thus it is appropriate for describing the interactions of the substituent with electron deficient fulvene ring. The values of sigma_p+ constants are taken from Ref20 [Stepień BT, Cyrański MK, Krygowski TM (2001) Chem Phys Lett 350:537.] and the proper citation is now included in the text.

6) It is missed in the text that points on the graphs in Figures are plotted for original compounds and 22 derivatives.

Reply: We now added the sentence "Dependences plotted in Figures 4-18 are plotted for these substituents plus unsubstitueted compounds" at the end of Methods section.

7) The ratio in the last paragraph on page 4 seems incorrect. The numbers $0.269 / 0.184$ do not appear in the Figures. The authors, probably need to correct them to $0.245 / 0.1546$ to make them consistent to Figs $4 \& 6$.

Reply: We thank the Referee for finding this error. Indeed the $0.269 / 0.184$ values came from the different set of substituents and the correct ratio is $0.245 / 0.1546=1.58$

This is now corrected in the paper on page 5 .

8) It would be interesting if the authors could give their comments on the numbers 1.44 and 0.06 entering the expression on page 5 above Fig.4.

Reply: The explatation is already given on page 5:" When pEDA values for fulvene and benzene derivatives are plotted each other, (Fig. 8) the regression shows qualitatively the same picture: the substituent effect on the pi-electron population in fulvene is 1.44 times greater than for benzene ring (eqation 3). This difference in sensitivity on the substituent effect is caused by strong pi-electron accepting characteristics of fulvene ring, which contain 5 pi-electrons and tends to achieve the Huckel value $4 \mathrm{~N}+2$ electrons; in the case of benzene containing 6 electrons no such effect takes place". The free factor 0.06 in the equation (3) is just a random error and ideally should be zero. In the revised version of the manuscript it is ommited.

9) The acronym "cc" standing for "correlation coefficient" is not defined in the text. How is it calculated?

Reply: We now added the explanatory sentence on page 5: "In the following figures CC means Correlation Coefficient". The correlation coefficient is calculated in the automatic way by the Microsoft Excel program. 
10) The sentence above Fig. 12 states: "... C1 position ... is ... more sensitive than..." Sensitive to what?

Reply: We mean sensitivity to substituent effect and this is now specified in the text.

11) What does it mean: "averaged C2, C5 atoms" (see the caption to Fig. 13).

Reply: The Referee is right that this sentence is awkward. We changed it to "Averaged occupations of C2, C5 positions". We corrected it also in the caption of Figs. 10, 11 and 14.

12) What is "HOMA" started to be mentioned from page 12.

Reply: HOMA means Harmonic Oscillator Model of Aromaticity and is a geometry-based aromaticity indiex. We now added two references on page 13.

13) The axis's titles in almost all figures should be revised. See Fig. 15 for example. It should be something like that: "occupation of pi-orbitals of $\mathrm{C}$ in para-position in benzene".

Reply: We believe that short axis titles are easier to read so we leave our notation only slightly improved but full description is in the caption to figures..

14) What is $R^{\wedge} 2$ on the graphs?

Reply: R2 below the regression equation means the square of correlation coefficient. As the correlation coefficient is given we removed the R2 values in the revised manuscript.

There are a lot of typos, that the authors were able to correct themselves before submission. However, they did not do that. Some of the typos are listed below.

1) The references in brackets should be reformatted to have a space in front of the opening backet.

Reply: This is now corrected

2) The graphs should have white background.

Reply: This is now corrected

3) Third line of Introduction: "benzene is" should read "benzene it is".

Reply: We changed this sentence to "Fulvene is also chemically reactive, whereas benzene is rather inert"

4) Next to the last sentence of the same paragraph: "monosubstituted substituted" reads bad.

Reply: This is now corrected 
5) Please, check the words with prefix "para", like parameters and comparable. You can find corresponding typos in the sentence atop Eq.(2) and under Fig. 17.

Reply: This is now corrected

6) The word "monosubstituted" in the first sentence of Results and discussion is written in two different ways. The second way is "mono-substituted".

Reply: We changed it now to: "Let us begin with a glimpse at the substituent effect in exo-cyclically monosubstituted fulvene and benzene presented by means of resonance structures"

7) The same is about "electron - donating" and "electron accepting".

Reply: This is now corrected

8) The last sentence on page 4: "... are plotted each other". Probably, the word "against" is missed.

Reply: This is now corrected

9) The fonts in the Figs 2 - 18 are too small.

Reply: We changed font size according to Reviewer suggestion

10) The vertical axis in Fig. 4 is named "pEDA(5)" instead of "pEDA(F)". The horizontal axis's name contains a redundant word "calc".

Reply: This is now corrected

11) The vertical axes in Fig. 5 and 7 have 5 redundant zeroes after the decimal point.

Reply: This is now corrected

12) The vertical axis in Fig. 7 is named "NICS" instead of "NICS(B)". The horizontal axis's name is "pEDAbenzene)", but it should be "pEDA(B)".

Reply: This is now corrected

13) The first sentence on page 9: "Fig. 12 present ..." should be "presents". The entire sentence should be revised anyway because it looks confusing. It should read "... dependence of pi-orbitals occupation of $\mathrm{C} 1 \ldots .$.

Reply: This is now corrected

14) The second sentence on page 10: "The slopes of C1atom ..." This sounds strange.

Reply: This is now corrected

15) Next to the last sentence of the first paragraph on page 13: "pi-electron sproperties". 
Reply: This is now corrected

16) The first sentence of the Conclusions: "correlate" should be corrected to "correlates".

Reply: This is now corrected

I do not think I have listed all of misprints and unclear sentences. The manuscript needs to be read critically and corrected accordingly.

Reply: We have done our best to correct remaining mistakes. 


\title{
Natural bond orbital approach to the transmission of substituent effect through the fulvene and benzene ring systems
}

Received: 11.03.2010 / Accepted: 11.05.2010

Wojciech P. Oziminski ${ }^{1,2, 凶}$ and Tadeusz M. Krygowski ${ }^{3}$

${ }^{1}$ National Medicines Institute, Chełmska 30/34, 00725 Warsaw, Poland

${ }^{2}$ Institute of Nuclear Chemistry and Technology, Dorodna 16, 03195 Warsaw, Poland

${ }^{3}$ Department of Chemistry, University of Warsaw, Pasteura 1, 02093 Warsaw, Poland

${ }^{\circledR}$ Tel. +48 228515230 ext.166; Fax: +48 2284106 52; Email: wojozim@ gmail.com

\begin{abstract}
Electronic structure of 22 monosubstituted derivatives of benzene and exocyclically substituted fulvene with substituents: $\mathrm{B}(\mathrm{OH})_{2}, \mathrm{BH}_{2}, \mathrm{CCH}, \mathrm{CF}_{3}, \mathrm{CH}_{3}, \mathrm{CHCH}_{2}, \mathrm{CHO}, \mathrm{Cl}$, $\mathrm{CMe}_{3}, \mathrm{CN}, \mathrm{COCH}_{3}, \mathrm{CONH}_{2}, \mathrm{COOH}, \mathrm{F}, \mathrm{NH}_{2}, \mathrm{NMe}_{2}, \mathrm{NO}, \mathrm{NO}_{2}, \mathrm{OCH}_{3}, \mathrm{OH}, \mathrm{SiH}_{3}, \mathrm{SiMe}_{3}$ were studied theoretically by means of Natural Bond Orbital analysis. It is shown, that sum of $\pi$ electron population of carbon atoms of the fulvene and benzene rings, $p \operatorname{EDA}(F)$ and $p E D A(B)$, respectively correlate well with Hammett substituent constants $\sigma_{\mathrm{p}}{ }^{+}$and aromaticity index NICS. The substituent effect acting on pi-electron occupation at carbon atoms of the fulvene ring is significantly stronger than in the case of benzene. Electron occupations of ring carbon atoms (except $\mathrm{C} 1$ ) in fulvene plotted against each other give linear regressions with high correlation coefficients. The same is true for ortho- and para-carbon atoms in benzene. Positive slopes of the regressions indicate similar for fulvene and benzene kind of substituent effect - mostly resonance in nature. Only the regressions of occupation at carbon atom in meta- position of benzene against ortho- and para-positions gives negative slopes and low correlation coefficients.
\end{abstract}

Keywords $\quad \mathrm{NBO} \cdot \mathrm{DFT} \cdot$ Fulvene $\cdot$ Substituent effect $\cdot p$ EDA 


\section{Introduction}

Fulvene, a non-alternant isomer of benzene differs from it by almost all possible characteristics. It is unstable, its ASE (aromatic stabilization energy) equals to -3.1 whereas for benzene is $32.4 \mathrm{kcal} \mathrm{mol}^{-1}$ [1]. Fulvene is also chemically reactive [2], whereas benzene is rather inert [3]. Substituent effects influence the fulvene ring much stronger [4] than benzene [5]. In the case of benzene, typical approaches concern the di-substituted species, in which one group is fixed (so called "reaction site", Y) and another one, X, varies [6-10]. Thus, the charge transfer in benzene derivatives takes place between $\mathrm{X}$ and $\mathrm{Y}$ and is transmitted by the aromatic ring [11]. In these cases a classical measure of transmission is just reaction constant $\rho$ which compared for two systems indicates in which of them the transmission is easier, or in other words which of them is more sensitive for substituent effect $[12,13]$. Transmission depends on nature of the reaction, medium in which it is carried out and obviously on the distance between the substituent and the reaction site $[14,15]$. In cases where there is no experimental study in which the Hammett-like approach is applied to physicochemical properties but instead some quantum-chemically derived quantities, a similar understanding of the transmission can be in use e.g. linear regression between $2 \mathrm{p}$ occupations for two atoms in a ring may indicate which of them is stronger influenced by a substituent. In the case of fulvene, most studies and interpretations of the substituent effects on structural and other properties are related to the exocyclic substitution [16-21]. Most aromatic indices exhibit strong variability and intercorrelate for 6-substituted derivatives of fulvene [21] which is not the case for monosubstituted benzene derivatives [11,22]. Moreover, in the case of strongly electron donating substituents, fulvene exhibits clearly aromatic properties [21]. Due to these differences in response to substituent effects, a comparison of substituent effects influence on electron structure of fulvene and benzene seems to be interesting and therefore is subject of this paper.

Some questions arise: how the pi-electron structure looks like for the ring of fulvene and for the linking bond between the ring and the substituent (C1C6 bond, see Fig. 1). Then, how in detail the substituents affect pi-electron population for individual carbon atoms in 6substituted fulvene derivatives. Finally, we intend to show a difference between the substituent effect in alternant hydrocarbon exemplified by benzene and non-alternant one fulvene. 


\section{Methods}

All calculations were performed at the B3LYP/6-311+G(d,p) level of theory using Gaussian 03 suite of programs [23]. Geometry optimizations were followed by frequency calculations to prove that the obtained stationary points are true minima on the potential energy surface. Natural Bond Orbital [24] analysis was performed by NBO 5.G program interfaced to Gaussian03. NICS [25] aromaticity index was calculated as a shielding constant of a ghost atom located at the geometric center of the ring.

The $p E D A$ [acronym from: pi Electron Donor-Acceptor] index was calculated by summation of the occupations of $2 p_{z}$ natural atomic orbitals (NAOs) of benzene ring carbon atoms and subtracting number $6-$ as for the ideal sextet (Eq. 1). This definition is slightly modified comparing to the original one [26].

$$
p E D A(B)=\sum_{j=1}^{6} \pi_{\text {benzene }}^{j}-6
$$

where $\mathrm{j}$ index runs over all six benzene carbon atoms and $\pi_{\text {benzene }}$ is the occupation of the $\mathrm{j}$-th $2 p_{z} \mathrm{NAO}$.

For the fulvene ring the definition is similar (Eq. 2) with the exception that the summation runs over only five atoms of the ring and to obtain $p E D A(F)$ as relative value to the unsubstituted fulvene molecule we subtract the number 5. In this way the $p E D A(F)$ parameter is comparable with that for benzene derivatives.

$$
p \operatorname{EDA}(F)=\sum_{j=1}^{5} \pi_{\text {fulvene }}^{j}-5
$$

The $\mathrm{j}$ index runs over all five fulvene ring carbon atoms and $\pi_{\text {fulvene }}$ is the occupation of the $\mathrm{j}$ th $2 p_{z}$ NAO.

22 substituted species span a wide range of substituents with varying donor-acceptor properties: $\mathrm{B}(\mathrm{OH})_{2}, \mathrm{BH}_{2}, \mathrm{CCH}, \mathrm{CF}_{3}, \mathrm{CH}_{3}, \mathrm{CHCH}_{2}, \mathrm{CHO}, \mathrm{Cl}, \mathrm{CMe}_{3}, \mathrm{CN}, \mathrm{COCH}_{3}, \mathrm{CONH}_{2}$, $\mathrm{COOH}, \mathrm{F}, \mathrm{NH}_{2}, \mathrm{NMe}_{2}, \mathrm{NO}, \mathrm{NO}_{2}, \mathrm{OCH}_{3}, \mathrm{OH}, \mathrm{SiH}_{3}, \mathrm{SiMe}_{3}$ and all of them plus an unsubstituted compound are taken into account in Figs. 4-18. 


\section{Results and discussion}

Let us begin with a glimpse at the substituent effect in exo-cyclically monosubstituted fulvene and benzene presented by means of resonance structures. Fig. 2 and 3 present the resonance structures in which $\mathrm{R}$ may be either electron donating (D) or electron accepting (A). The ring carbon atoms with only two single bonds to other carbon atoms are charged, either negatively when $\mathrm{R}=\mathrm{D}$, or positively if $\mathrm{R}=\mathrm{A}$.

$<$ Figure 2>

$<$ Figure 3>

There are three aspects to be considered: (i) how differences in substituent effect transmission through benzene and fulvene affect the overall electron structure of benzene and fulvene rings, (ii) how they operate for individual carbon atoms in the rings and (iii) how the changes in the ring correlate with those in the transmitter of the substituent effect: $\mathrm{C} 1=\mathrm{C} 6$ moiety.

First, let us consider the overall effects observed in fulvene and benzene derivatives. In both cases $p E D A$ [26] correlate well with Hammett ${\sigma_{\mathrm{p}}}^{+}[20,27]$ and aromaticity index NICS [25] as shown in Fig. 4 through 7. The first observation is that $\pi$-electron populations at carbon atoms of the ring in fulvene and benzene, $p E D A(F)$ and $p E D A(B)$ plotted against $\sigma_{\mathrm{p}}{ }^{+}$differ dramatically in values of the slopes of the regressions. Sensitivity of fulvene and benzene rings on substituent effect estimated by ratio of the slopes for fulvene and benzene derivatives is $0.245 / 0.155=1.58$. It means for fulvene is 1.58 times greater than in benzene derivatives. Alike is a situation for scatter plots of $p E D A$ against NICS. When $p E D A$ values for fulvene and benzene derivatives are plotted against each other, (Fig. 8) the regression shows qualitatively the same picture, the substituent effect on the pi-electron population at carbon atoms in fulvene is 1.44 times greater than for benzene ring (Eq. 3). This difference in sensitivity on the substituent effect is caused by a strong pi-electron accepting characteristics of fulvene ring, which contains 5 pi-electrons and tends to achieve the Hückel value $4 \mathrm{~N}+2$ electrons; whereas in the case of benzene containing 6 electrons no such effect takes place.

$$
p \operatorname{EDA}(\mathrm{F})=1.44 * p \operatorname{EDA}(\mathrm{B})
$$

In the following figures cc means correlation coefficient. 
$<$ Figure 4-8>

Next, let us consider how the population of pi electrons on the individual carbon atoms in fulvene ring depends on substituent constants. Figs. 9-11 present appropriate dependences.

$<$ Figure 9-11>

All regressions presented in Fig. 9-11 have acceptable correlation coefficients and hence their regression slopes may be subject of further analysis. As we see, the slope for dependence of $2 p_{z}$ occupation at $\mathrm{C} 1$ is 2.8 times greater than for mean value for $2 p_{z}$ occupations at $\mathrm{C} 3$ and $\mathrm{C} 4$ and 5.7 times greater than mean value for $2 p_{z}$ occupations at C2 and C5 despite of the longer distance from substituent to $\mathrm{C} 3$ and $\mathrm{C} 4$ atoms.

Now, let us look at the direct comparison of substituent effect on pi-electron population at individual carbon atoms in benzene and fulvene. Fig. 12-14 show the occupations at carbon atoms which are distant from the substituent by one, two and three CC bonds. Fig. 12 presents the dependence of pi-orbital occupation of $\mathrm{C} 1$ in fulvene on pi-orbital occupation of orthocarbon atom in benzene. The slope of the regression is 1.45 and shows that occupation of carbon atom $\mathrm{C} 1$ in fulvene is 1.45 times more sensitive to the substituent effect than the ortho-carbon atom in benzene.

$<$ Figure 12-14>

A direct comparison reveals a very important difference between changes in $2 p_{z}$ occupation at carbon atoms in benzene and fulvene rings. The slopes of the regression of pi-occupation of $\mathrm{C} 1$ atom of fulvene vs. occupation of carbon atoms in ortho-position of benzene and of averaged occupations of $\mathrm{C} 3, \mathrm{C} 4$ atoms of fulvene $v s$. occupations of carbon atoms in paraposition of benzene are positive and with relatively high correlation coefficients. Completely different is the regression of occupations of averaged $\mathrm{C} 2, \mathrm{C} 5$ atoms of fulvene vs. metaposition of benzene. Its slope is negative and correlation coefficient is very low. How to interpret this strange result? As presented in Fig. 2 and 3, in the case of fulvene, all carbon atoms in the ring may communicate with the substituent by resonance effect, withdrawing or donating pi electrons from the substituent if it is donating/withdrawing in nature. That is not the case of benzene, where only two ortho-positions and one para- are able to communicate with the substituent by means of resonance effect. The meta-position is stronger influenced by inductive/field effect than by resonance [28, 29]. The inductive/field effect is mostly 
electrostatic in nature and acting through the space [30-32]. Thus, the pi-occupation at carbon atoms in meta- position of benzene has weak contribution from resonance effect, react via different mechanism on substituent effect than it is the case of fulvene in 2,5 positions.

This point is well supported by a direct comparison of slopes of the regressions of pi-electron occupation for pairs of resonance accessible carbon atoms in benzene and fulvene derivatives, shown in Fig. 15 and 16

$<$ Figure 15-16>

Despite the fact that there are two ortho-carbon atoms in benzene ring and only one paracarbon atom, the substituent effect acts in ortho-position much stronger than in para- as documented by the slope of regression shown in Fig. 15 which is equal to 1.44 with correlation coefficient 0.991 . In the case of the fulvene (Fig. 16) the slope for the regression of occupation at C1-vs. averaged values of occupation at C3 and C4 atoms is even larger2.67 and the correlation coefficient amounts to 0.959. It seems reasonable to relate this difference to much stronger withdrawing ability of $4 \mathrm{~N}+1$ ring of fulvene than that of benzene fulfilling the Hückel rule.

To support the conclusion dealing with a different mechanism presented in discussion of results shown in Fig. 12-14, we plotted the pi-electron occupation of carbon atoms in orthoagainst meta- position in benzene shown in Fig. 17. There are two important differences when compared with the picture in Fig. 15 and 16. The slope in Fig. 17 is negative and the correlation coefficient much lower. Additionally, it is also shown that the range of occupation changes in the case of carbon atoms in meta- position is only $0.02 \mathrm{e}$ whereas for atoms in para-position it is $0.16 \mathrm{e}$. This is in excellent agreement with the simple reasoning that results from Fig. 2 and 3: carbon atoms in meta-position in benzene is not accessible for resonance interactions (as far as only single excited resonance structures are concerned) [33] and other effects may play important role.

\section{$<$ Figure 17>}

Another aspect of changes in pi-electron structure of 6-substituted fulvene derivatives is a relation of parameters describing the C1C6 bond, the transmitter of the substituent to the ring, and the ring itself. Fig. 18 presents the dependence of HOMA aromaticity index [34, 35] on the C1C6 bond lengths. 
$<$ Figure 18>

It is clear that for pi-electron donating substituents $\left(\mathrm{NMe}_{2}, \mathrm{NH}_{2}, \mathrm{OMe}, \mathrm{OH}\right.$ and $\mathrm{F}$ in Fig. 18), parameters of the ring (HOMA) and of the bond (bond length) vary in line with a very high correlation coefficient $(\mathrm{cc}=0.970)$ indicating strong cooperation of pi-electron structure in the ring and in the bond. This agreement is dramatically broken for electron accepting substituents, which form a cluster of points below the line HOMA $=0$. For the latter case it may be interpreted as follows: both parts of molecules, the ring and the substituent from the point of view of $\pi$-electron properties, are the electron withdrawing moieties. Thus, there does not exist one dominant effect, but rather a composition of many effects, which contribute to the changes in geometry of both kinds of fulvene derivatives and hence lead to irregular changes.

\section{Conclusions}

(i) pi-electron population at carbon atoms of the ring - $p E D A$ in fulvene and benzene correlates well with substituent constant ${\sigma_{\mathrm{p}}}^{+}$and with aromaticity index NICS indicating that $p E D A$ may serve in some cases as a useful indicator of aromaticity.

(ii) pi-electron occupations of carbon atoms in benzene and in fulvene rings are mutually well correlated for positions ortho- and para- in benzene and 1 and 3,4 positions in fulvene with positive regression slopes, whereas for position meta-vs. 2,5 in fulvene correlation is much worse and with a significant negative slope.

(iii) Direct comparison by means of linear regression of pi- electron occupation at ortho- vs. meta- carbon atoms in benzene gives negative regression slope and weak correlation coefficient. This is explained by different mechanism of substituent effect on ortho- and meta- carbon atoms: the dominant resonance effect in the case of ortho-atoms and dominant inductive/field effect in the case of meta- positions.

(iv) The difference between substituent effect in benzene and fulvene is not only quantitative (greater effects in fulvene) but also in that, that in fulvene all carbon atoms in the ring communicate by resonance with the substituent whereas in benzene ring only ortho- and para-positions can do that. 


\section{Acknowledgments}

Computational Grant G31-10 from the Interdisciplinary Centre of Mathematical and Computer Modelling (ICM) at Warsaw University is gratefully acknowledged. 


\section{References}

1. Cyrański MK (2005) Chem Rev 105:3773-3811; isodesmic reaction \#11 in Table 13, p 3793

2. Lloyd D (1990) The Chemistry of Conjugated Compounds: To Be or Nor To Be Like Benzene. J Wiley, Chichester, pp 91-94

3. Smith MB, March J (2001) March's Advanced Organic Chemistry, Reactions, Mechanisms and Structure. J Wiley, pp 693-694

4. Stepień BT, Cyrański MK, Krygowski TM (2001) Chem Phys Lett 350:537-542

5. Krygowski TM, Ejsmont K, Stepien MK, Poater J, Sola M (2004) J Org Chem 69:66346640

6. Jaffe HH (1953) Chem Rev 53:191-261

7. Charton M (1981) Progr Phys Org Chem 13:119-251

8. Exner O (1988) Correlation Analysis of Chemical Data. Plenum Press, New York

9. Krygowski TM, Stępień BT (2005) Chem Rev 105:3482-3512

10. Exner O, Bohm S (2006) Curr Org Chem 10:763-778

11. Krygowski TM, Stepień BT (2004) Pol J Chem 68:2213-2217

12. Exner O (1972) In: Chapman NB, Shorter J (eds) Advances in Linear Free Energy Relationships. Plenum Press, London, chpt 1, pp 20-27

13. Godfrey M (1991) In: Zalewski RI, Krygowski TM, Shorter J (eds) Similarity models in organic chemistry, biochemistry and related fields. Elsevier, Amsterdam, pp 149-175

14. Hammett LP (1970) Physical Organic Chemistry, McGraw - Hill: New York, Chpt. IX, pp 251-290

15. Krygowski TM, Fawcett WR (1977) J Chem Soc Perkin II, 2033-2037

16. Ammon HL (1974) Acta Crys B30:1731-1738

17. Wingert LM, Staley SV (1992) Acta Cryst B 48:782-789

18. Krygowski TM, Ciesielski A, Cyranski MK (1995) Chem Papers 49:128-132

19. Peterson ML, Stranad JT, Markotan TP, Morales CA, Staley SV (1999) J Org Chem 64:9067-9076

20. Stepień BT, Cyrański MK, Krygowski TM (2001) Chem Phys Lett 350:537-542

21. Stepien BT, Krygowski TM, Cyrański MK (2002) J Org Chem 67:5987-5992

22. Krygowski TM, Stepien BT, Cyranski MK, Ejsmont K (2005) J Phys Org Chem 18:886891

23. Gaussian 03, Rev E.01 (2001) Gaussian Inc, Wallingford CT 
24. Reed AE, Curtiss LA, Weinhold F (1988) Chem Rev 88:899-926

25. Schleyer PvR, Maerker C, Dransfeld A, Jiao H, Hommes NJRvE (1996) J Am Chem Soc 118:6317-6318

26. Oziminski WP, Dobrowolski JC (2009) J Phys Org Chem 22:769-778

27. Hansch C, Leo A, Taft RW, (1991) Chem Rev 91:165-195

28. Taft RW, Lewis IC (1958) J Am Chem Soc 60:2436-2443

29. Exner O (1972) Chapt 1. In: Chapman NB, Shorter J (eds) Adv. In Free Linear Energy relationships. Plenum Press, London, pp 35-41

30. Bowden K, Grubbs EJ (1996) Chem Soc Rev 25:171-177

31. Wiberg KB (2002) J Org Chem 67:161-168

32. Wiberg KB (2002) J Org Chem 67:4787-4794

33. Krygowski TM, Palusiak M, Płonka A, Zachara-Horeglad JE (2007) J Phys Org Chem 20:297-306

34. Kruszewski J, Krygowski TM (1972) Tetrahedron Lett 3839-3842

35. Krygowski TM (1993) J Inf Comput Sci 33:70-78 


\section{Figure captions}

Fig. 1 The numbering scheme for the substituted fulvene molecule

Fig. 2 Resonance structures of the fulvene molecule

Fig. 3 Resonance structures of the benzene molecule

Fig. 4 Dependence of $p E D A(F)$ for fulvene on $\sigma_{\mathrm{p}}{ }^{+}$with $\mathrm{cc}=0.974$

Fig. 5 Dependence of $\mathrm{NICS}(\mathrm{F})$ on $p E D A(\mathrm{~F})$ with $c c=-0.963$

Fig. 6 Dependence of $p E D A(B)$ for benzene on ${\sigma_{\mathrm{p}}}^{+}$with $\mathrm{cc}=-0.933$

Fig. 7 Dependence of NICS(B) on $p E D A(B)$ for benzene with $c c=-0.945$

Fig. 8 Dependence of $p \operatorname{EDA}(\mathrm{F})$ on $p \operatorname{EDA}(\mathrm{B})$ with $c c=0.949$

Fig. 9 Dependence of $\pi$-occupation of $\mathrm{C} 1$ atom in fulvene on substituent constants $\sigma_{\mathrm{p}}{ }^{+}$ with $c c=-0.960$

Fig. 10 Dependence of the averaged $\pi$-occupation of C2 and C5 carbon atoms in fulvene on substituent cosntants $\sigma_{\mathrm{p}}{ }^{+}$with $\mathrm{cc}=-0.924$

Fig. 11 Dependence of the averaged $\pi$-occupation of C3 and C4 carbon atoms in fulvene on substituent constants $\sigma_{\mathrm{p}}{ }^{+}$with $\mathrm{cc}=-0.936$

Fig. 12 Dependence of $\pi$-occupation of $\mathrm{C} 1$ atom of fulvene on occupation of ortho-carbon atom in benzene with $\mathrm{cc}=0.986$

Fig. 13 Dependence of averaged $\pi$-occupations of C2, C5 atoms of fulvene on occupation of $m e t a$ - carbon atoms of benzene with $\mathrm{cc}=0.675$ 
Fig. 14 Dependence of averaged $\pi$-occupations of C3, C4 atoms of fulvene on occupations at carbon atom in para-position of benzene with $\mathrm{cc}=0.962$

Fig. 15 Dependence of $\pi$-occupation of ortho- on the $\pi$-occupation at para-carbon atoms in benzene derivatives with $\mathrm{cc}=0.991$

Fig. 16 Dependence of $\pi$-occupation in $C 1$-carbon atom on the averaged $\pi$-occupations at $\mathrm{C} 3, \mathrm{C} 4$ atoms in fulvene derivatives with $\mathrm{cc}=0.960$

Fig. $17 \pi$-occupations of ortho- $v$ s. meta- position in benzene derivatives with $\mathrm{cc}=-0.720$

Fig. 18 The dependence of HOMA of the ring on C1C6 bond lengths with $\mathrm{cc}=0.970$ 
Figure
Click here to download high resolution image

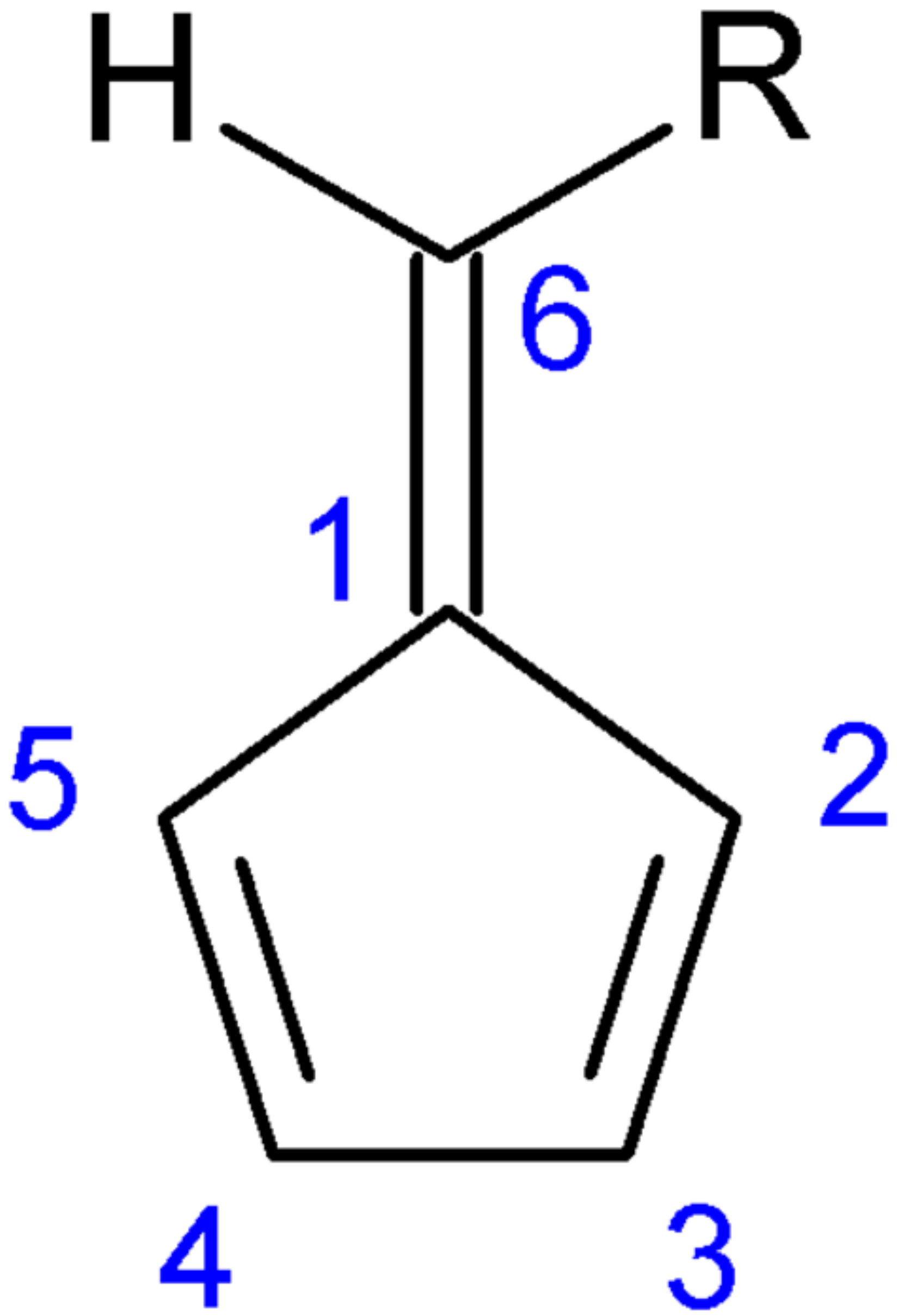




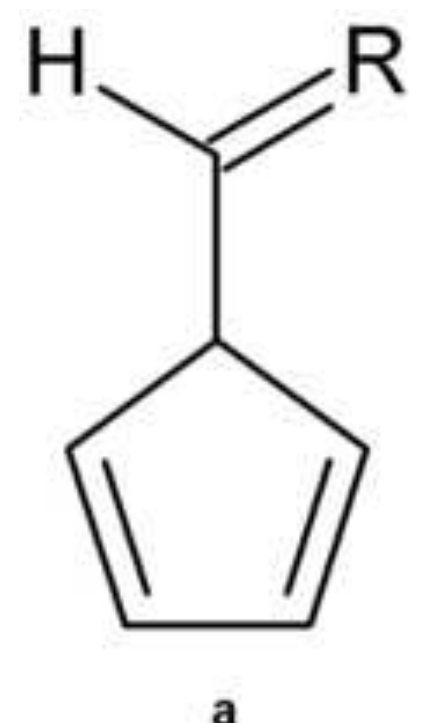

a

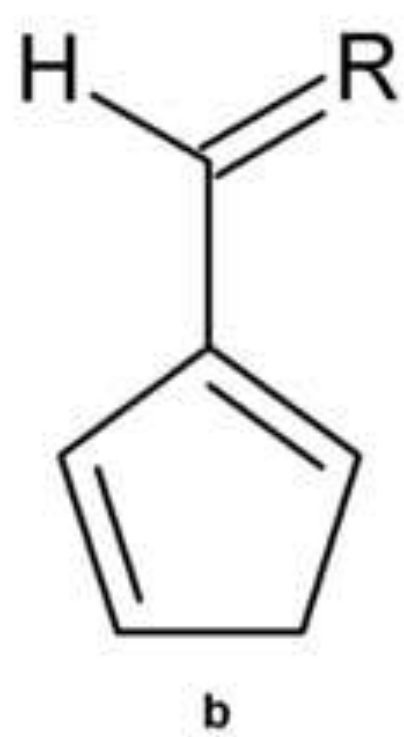

b
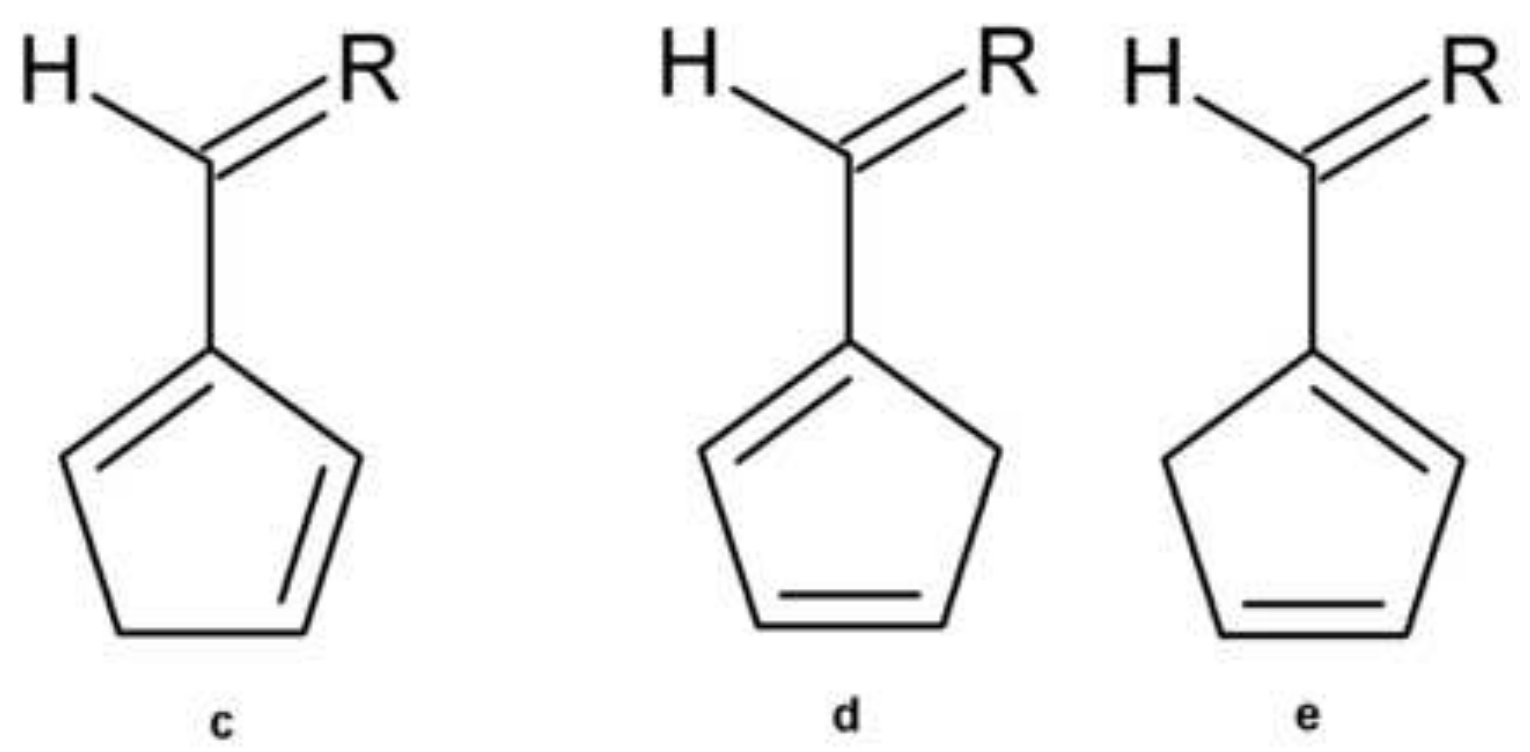


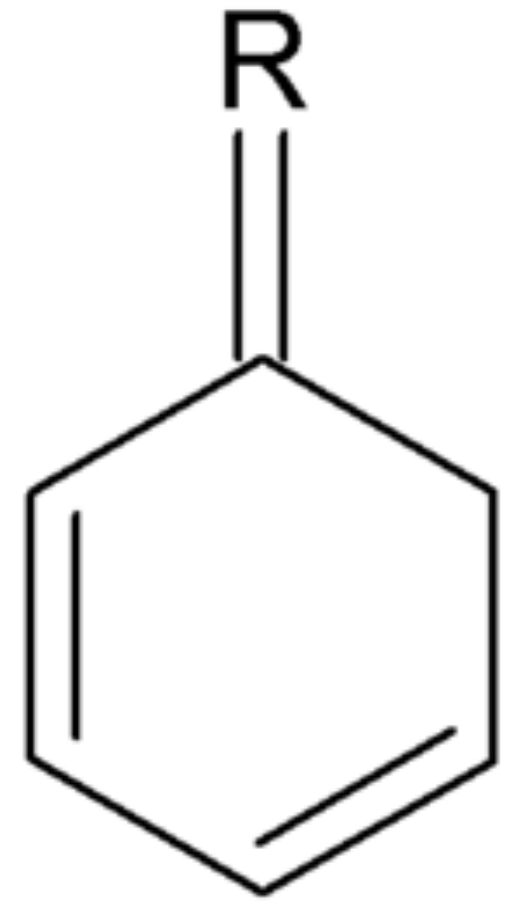

a

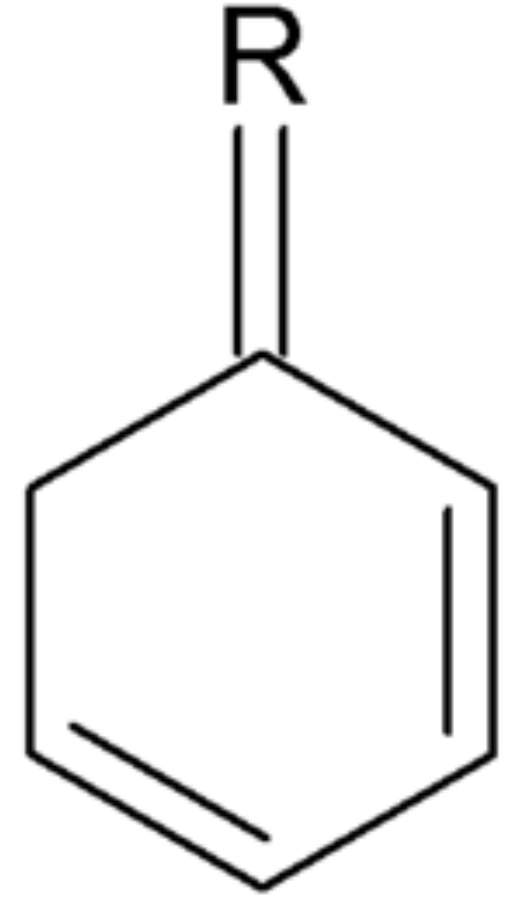

b

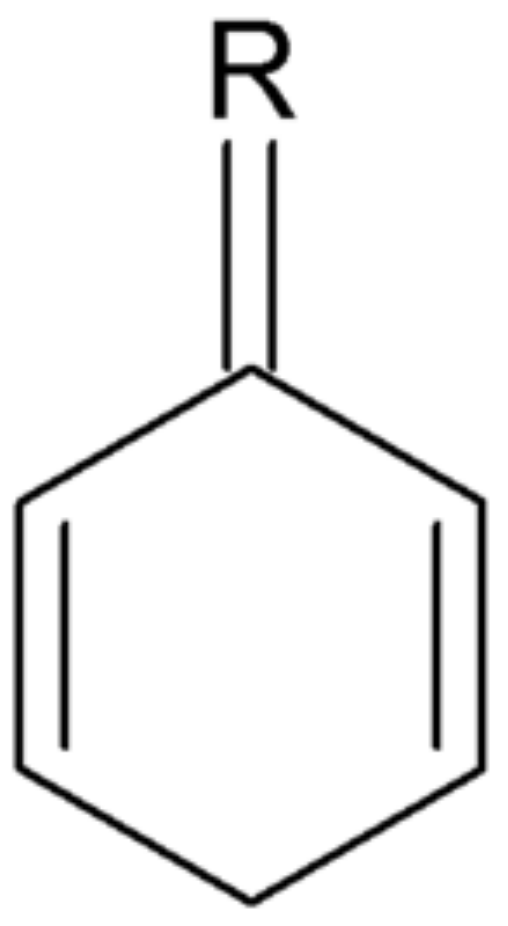

C 
Figure 4

Click here to download high resolution image

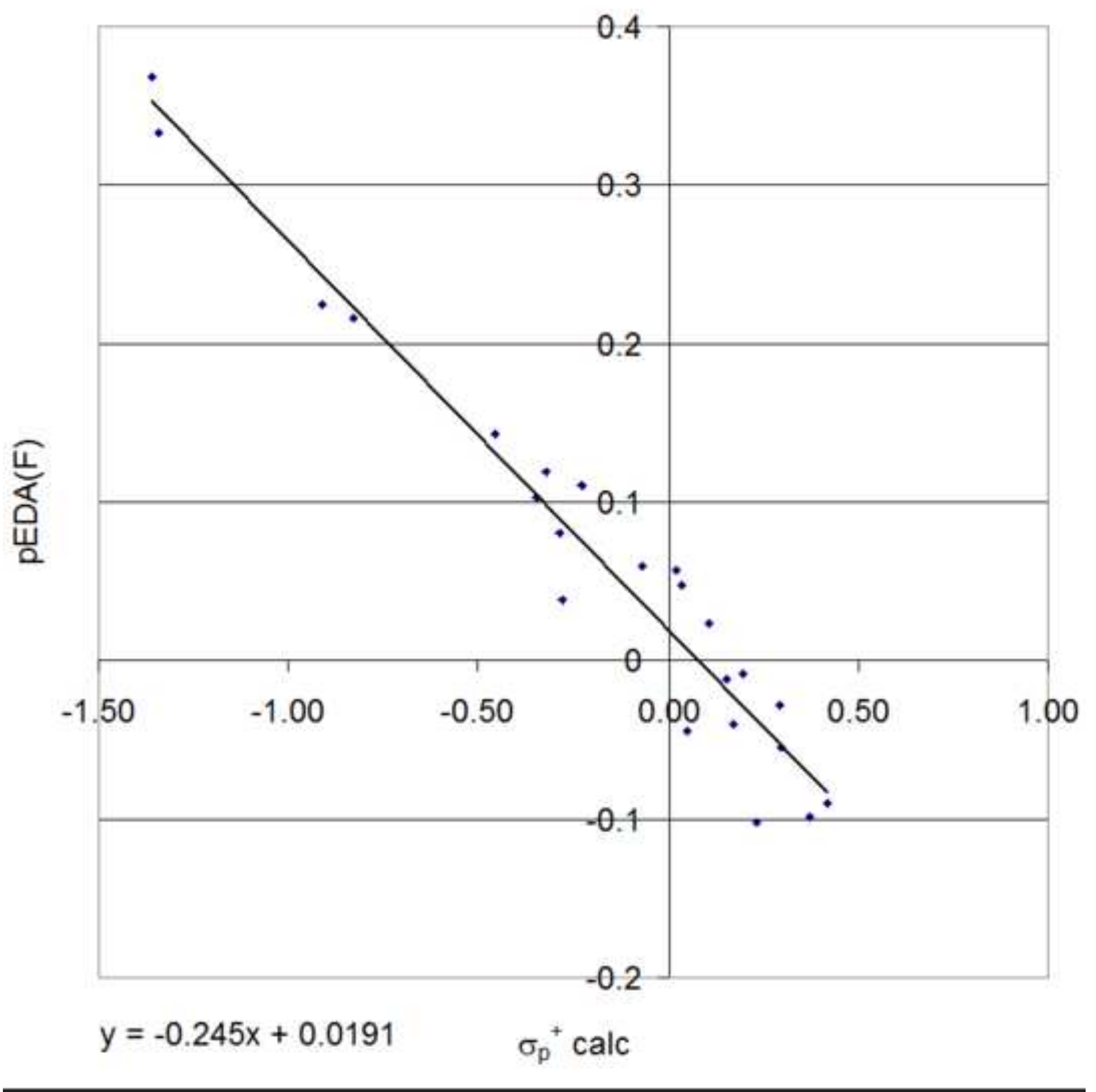


Click here to download high resolution image

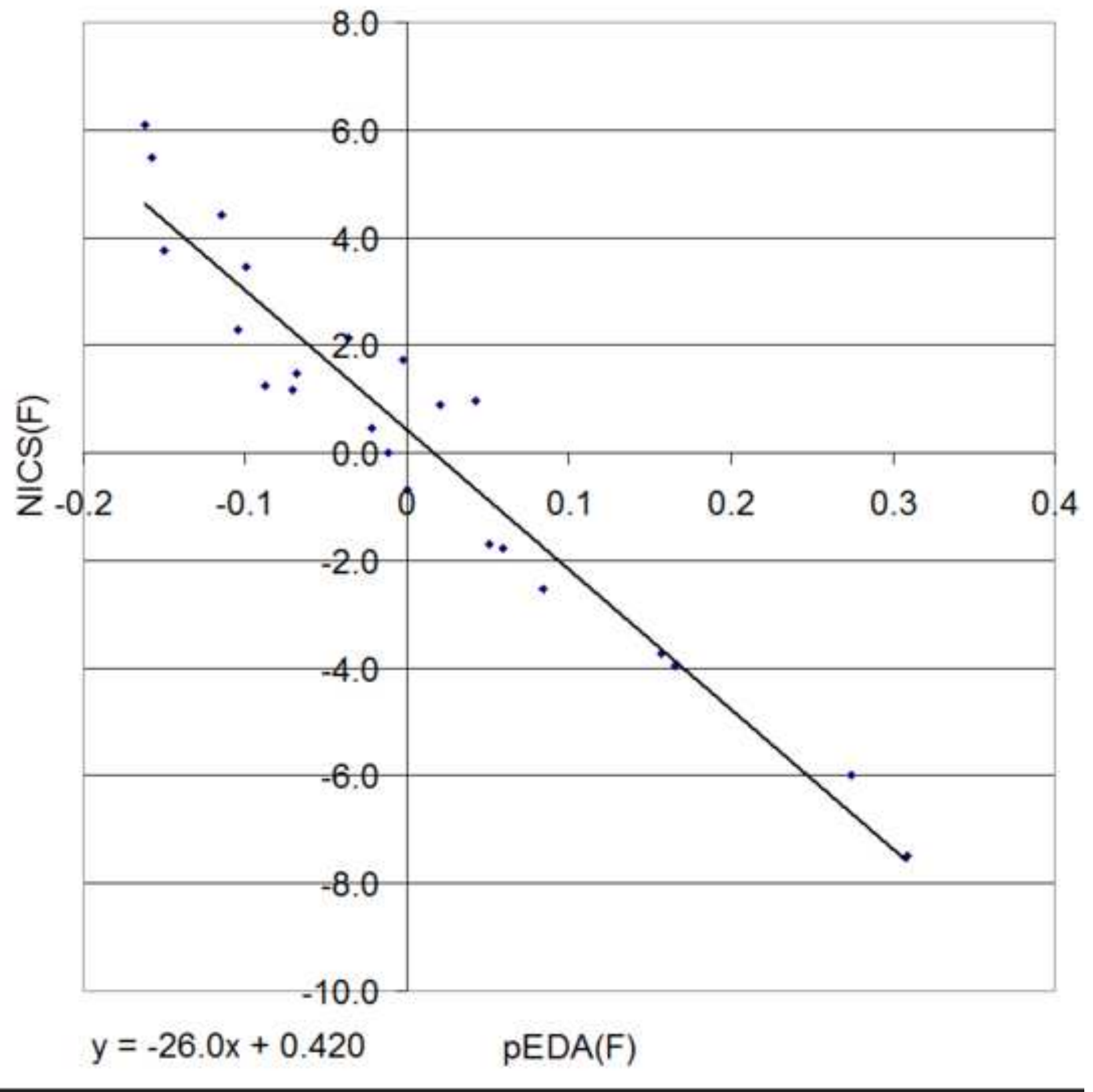


Figure 6

Click here to download high resolution image

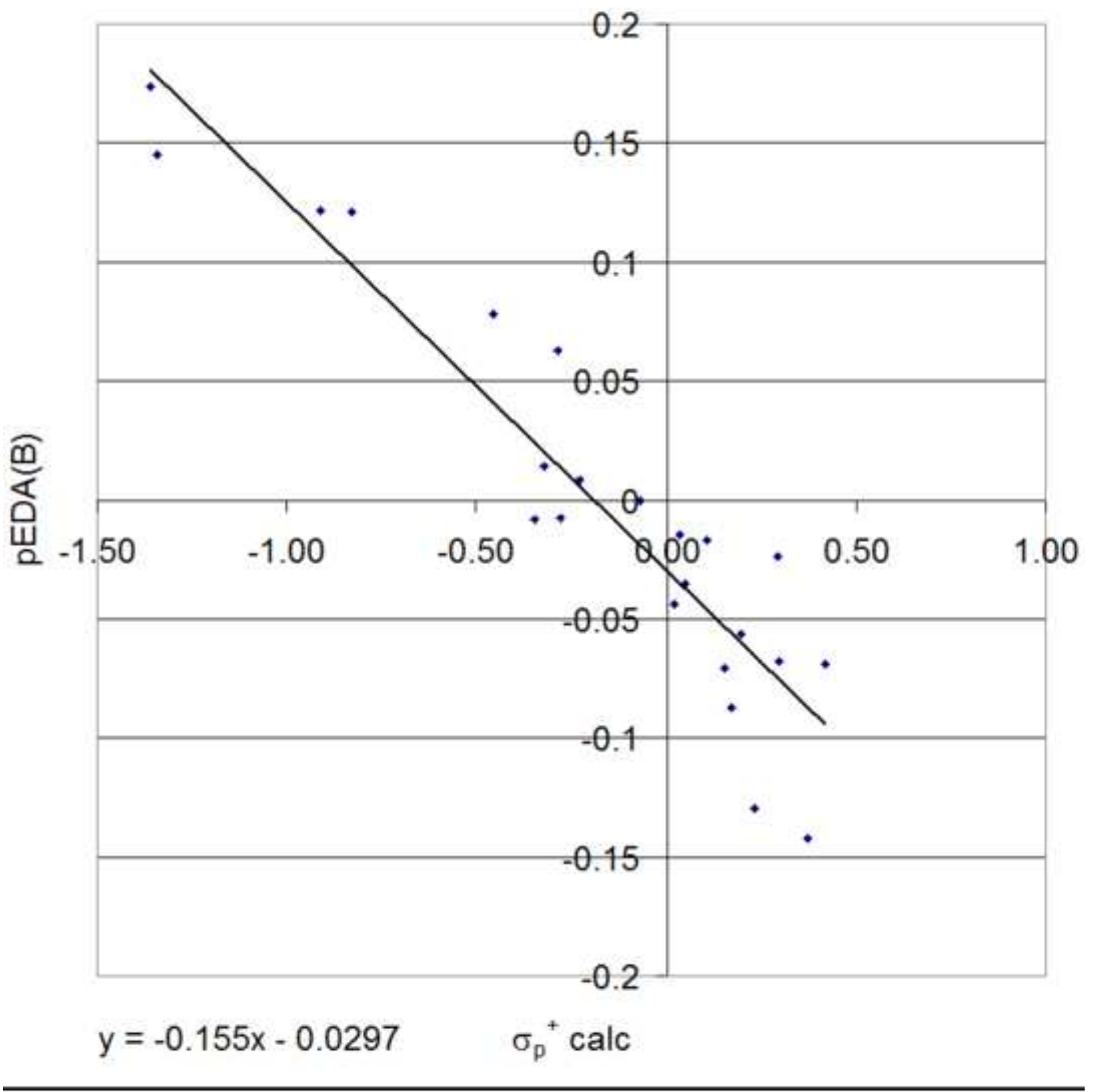


Figure 7

Click here to download high resolution image

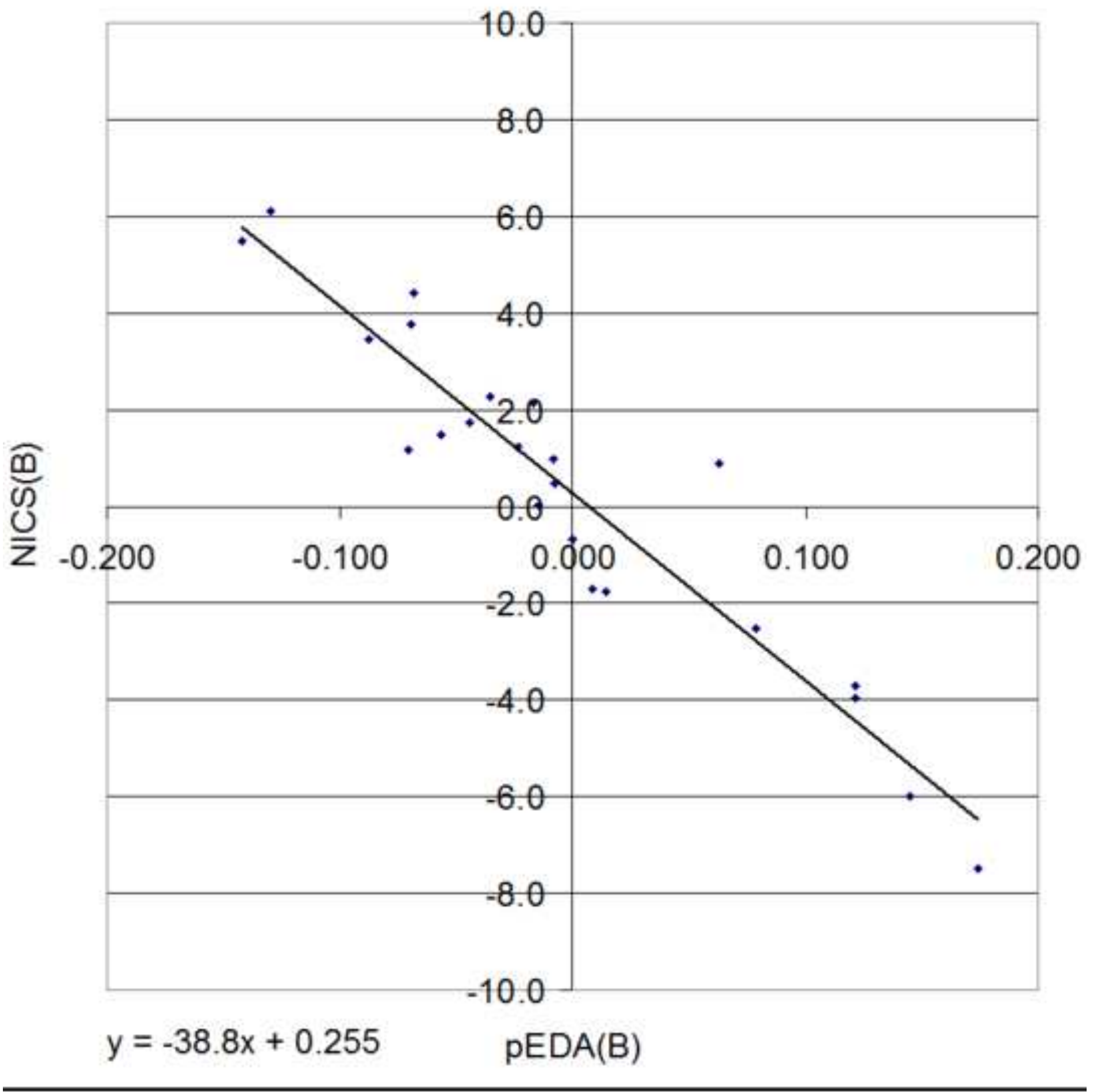


Figure 8

Click here to download high resolution image

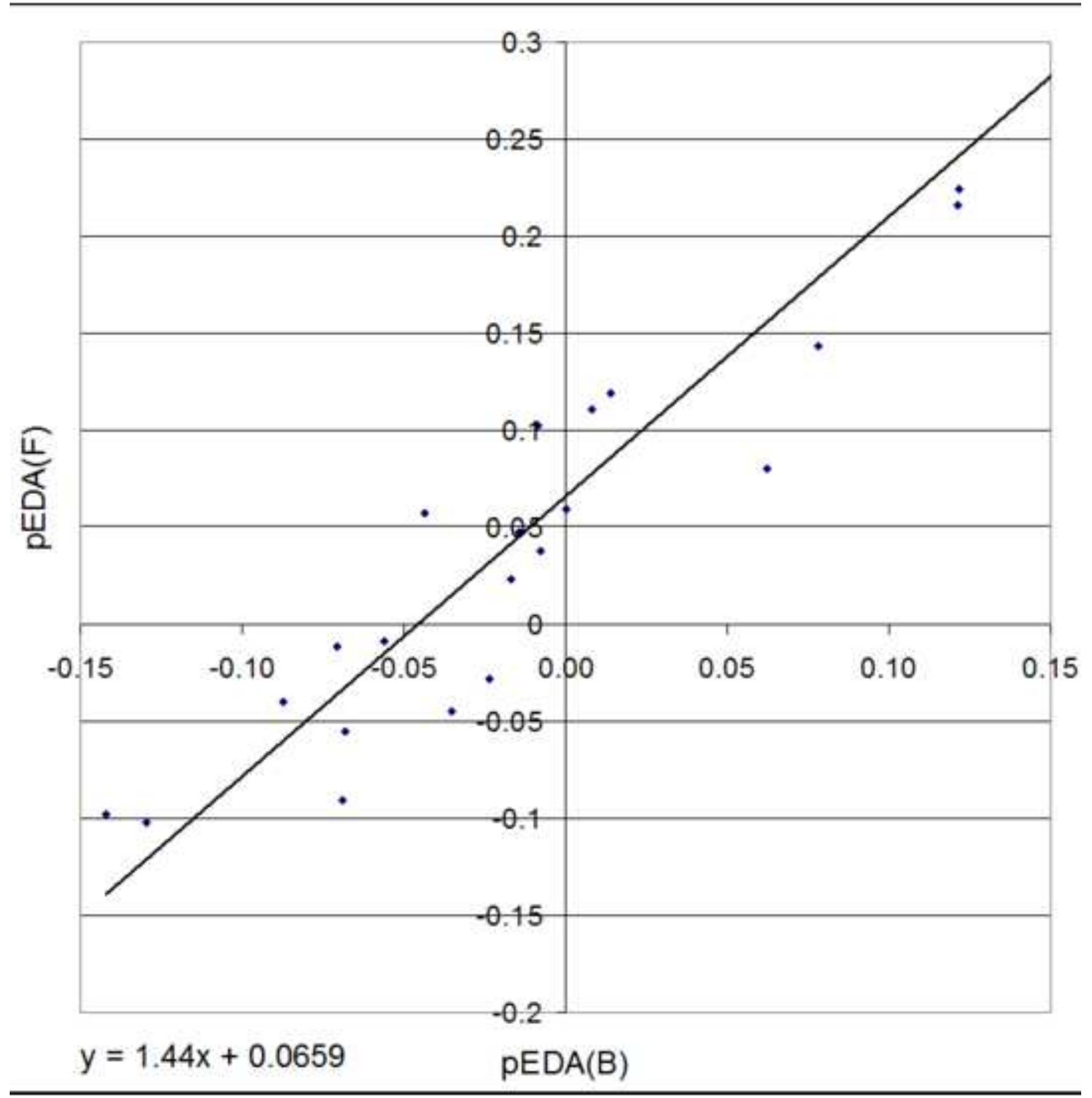


Figure 9

Click here to download high resolution image

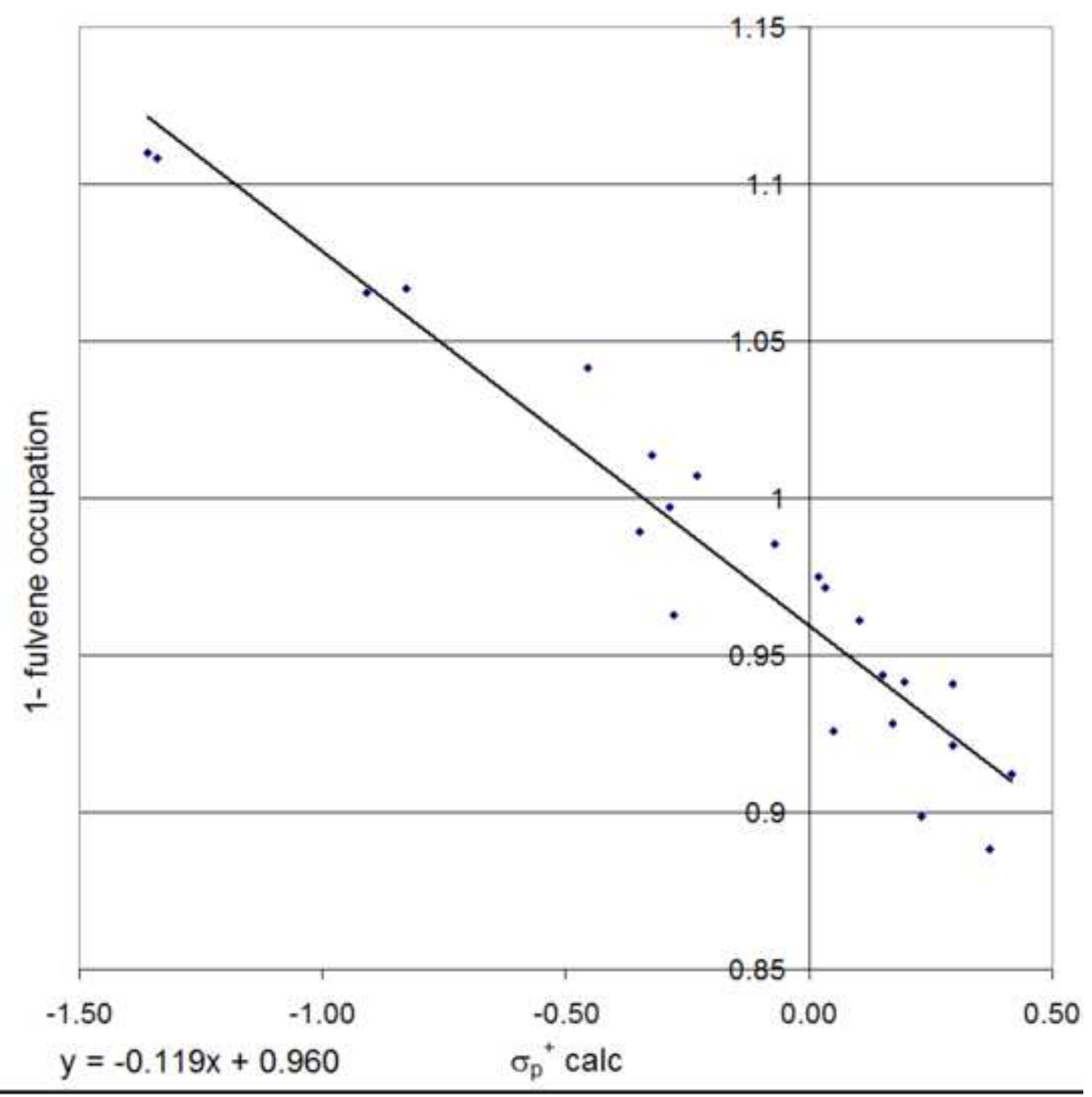


Figure 10
Click here to download high resolution image

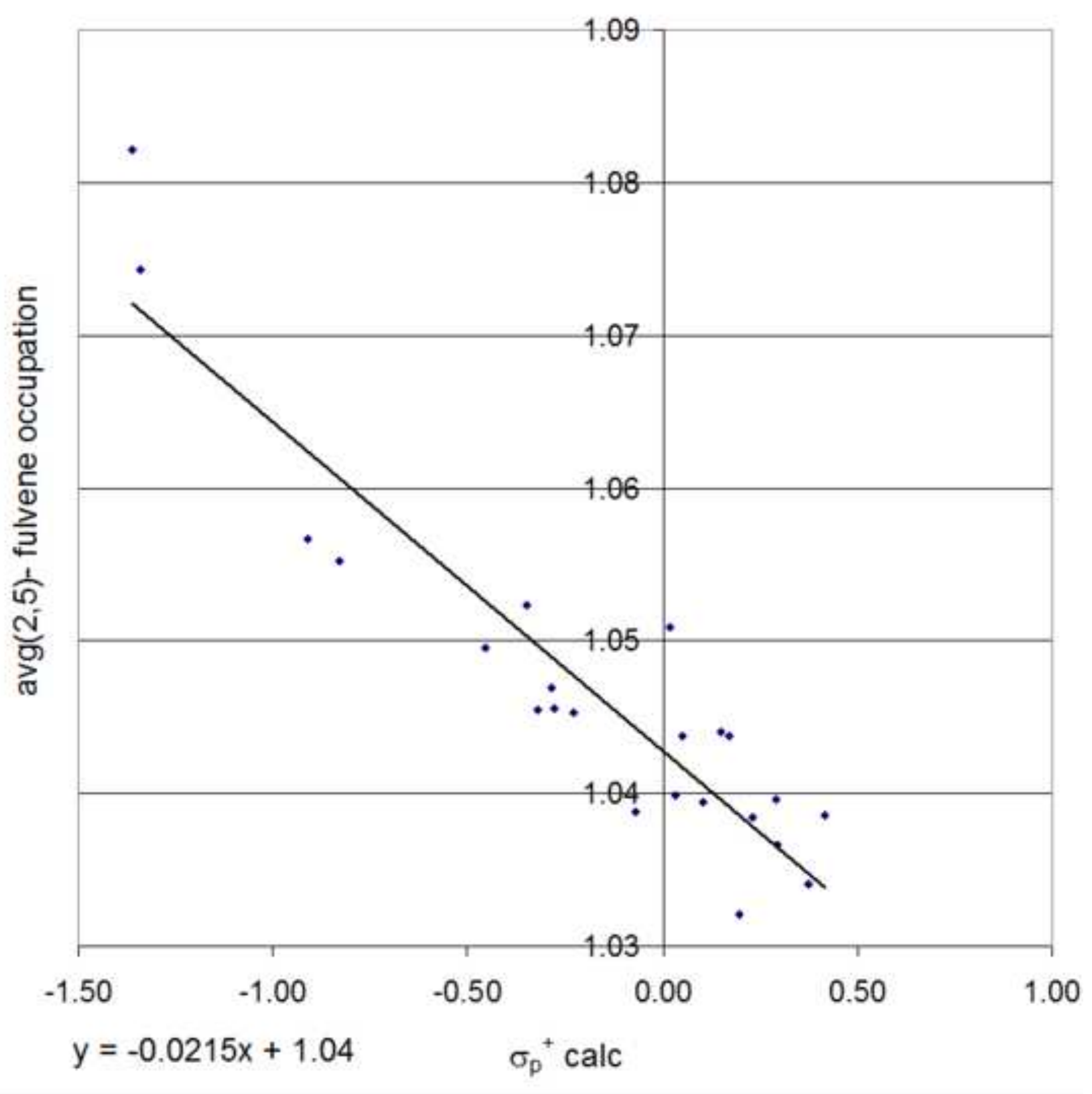


Figure 11
Click here to download high resolution image

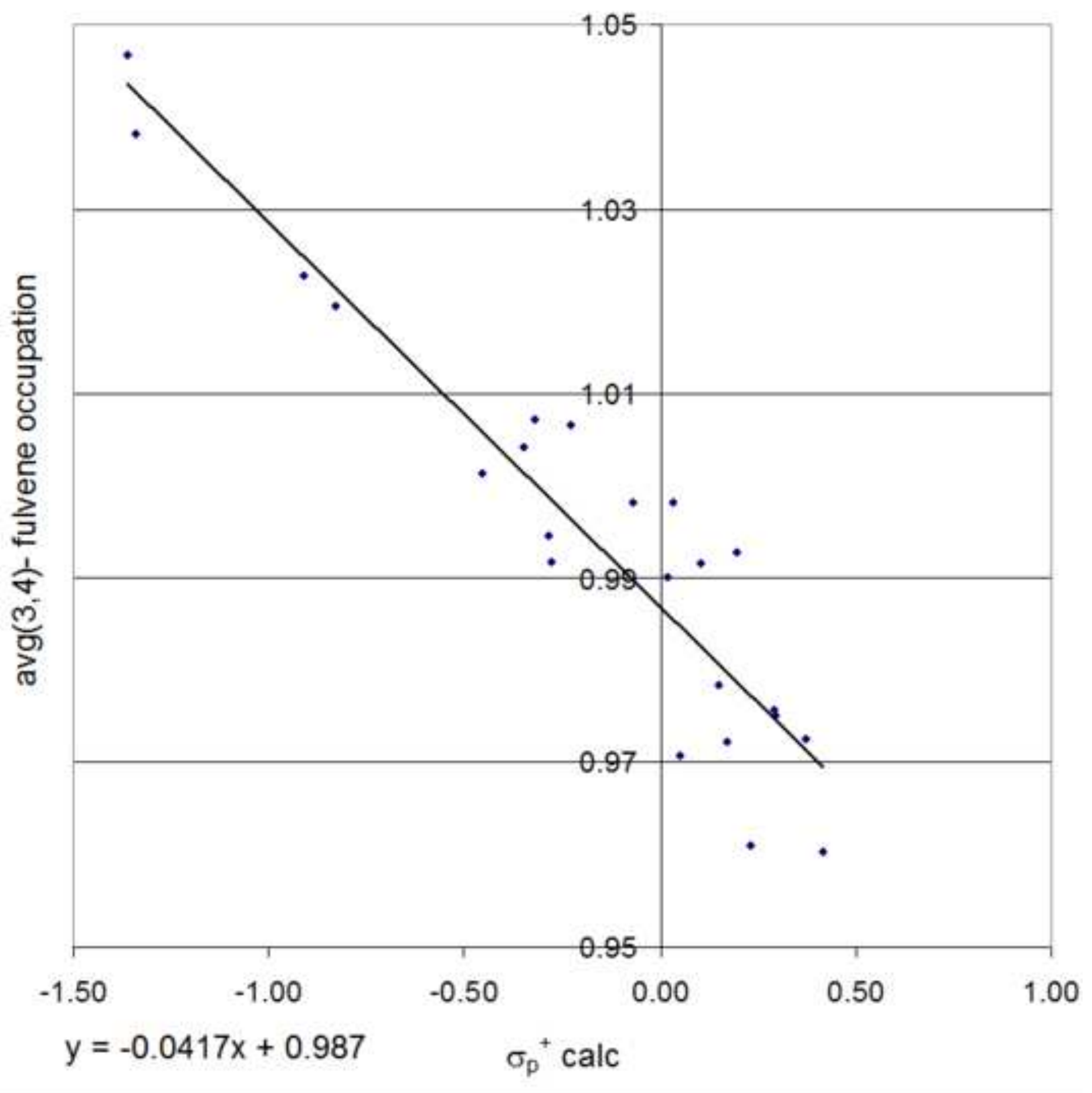


Figure 12
Click here to download high resolution image

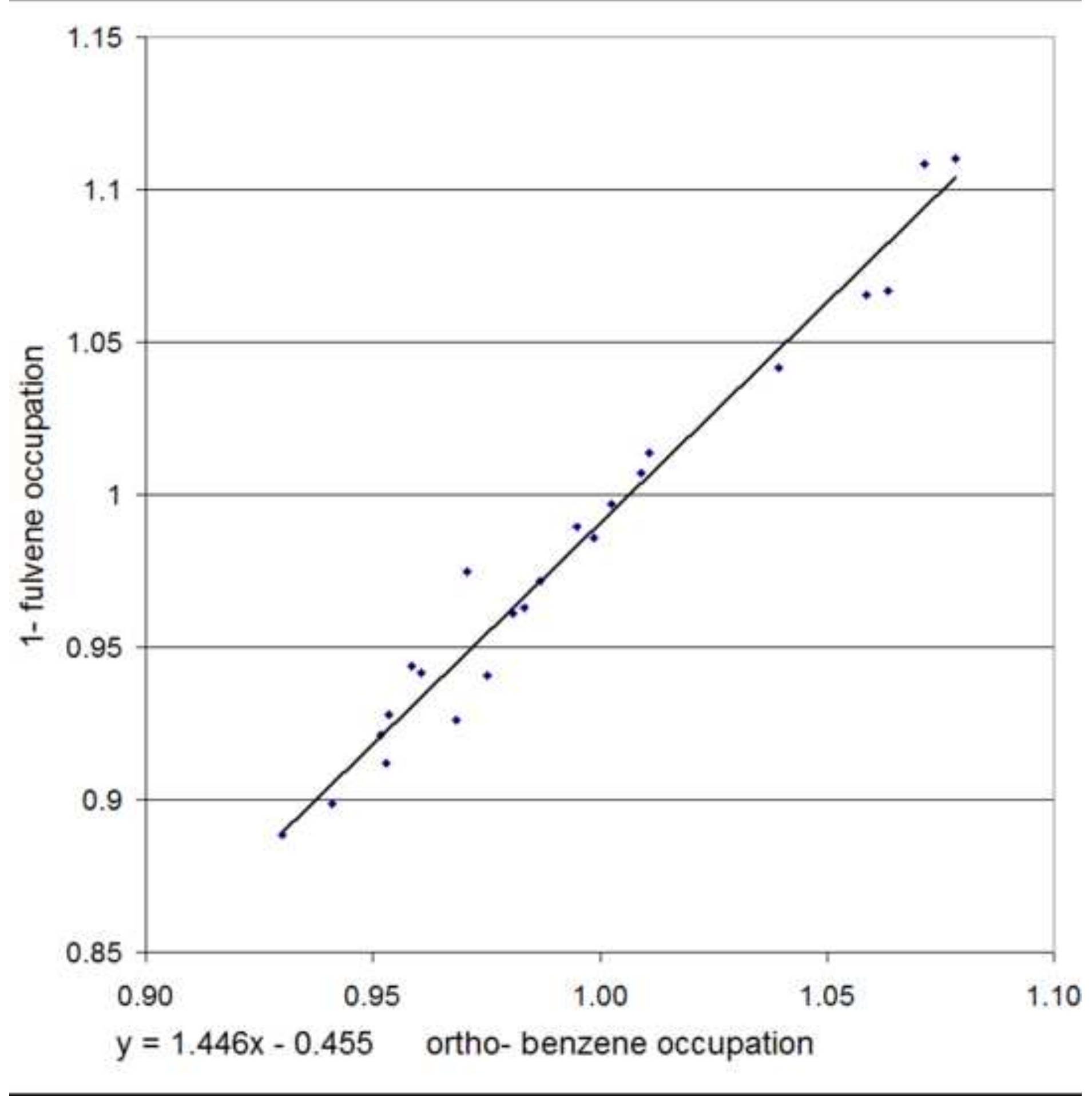


Click here to download high resolution image

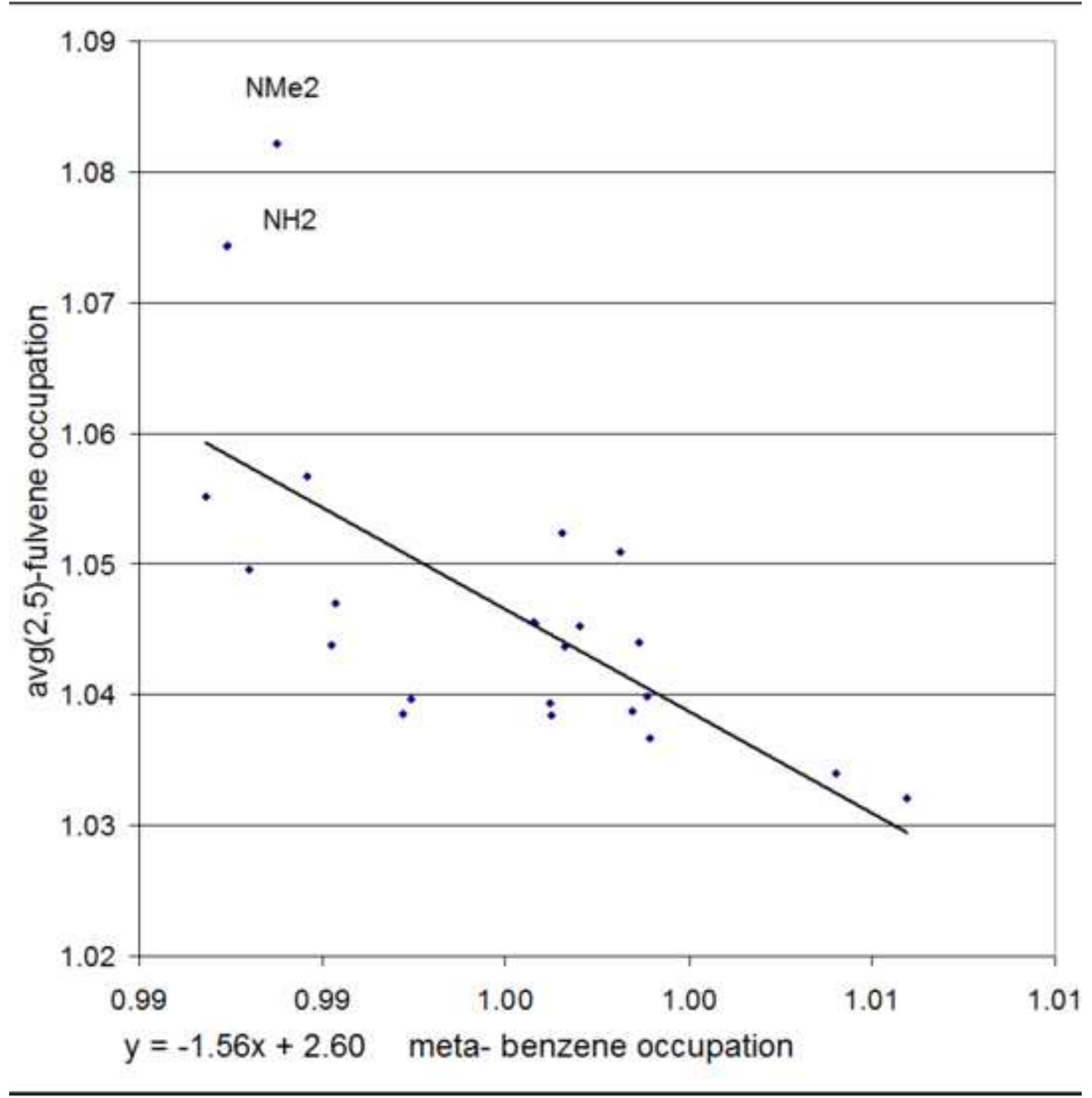


Figure 14
Click here to download high resolution image

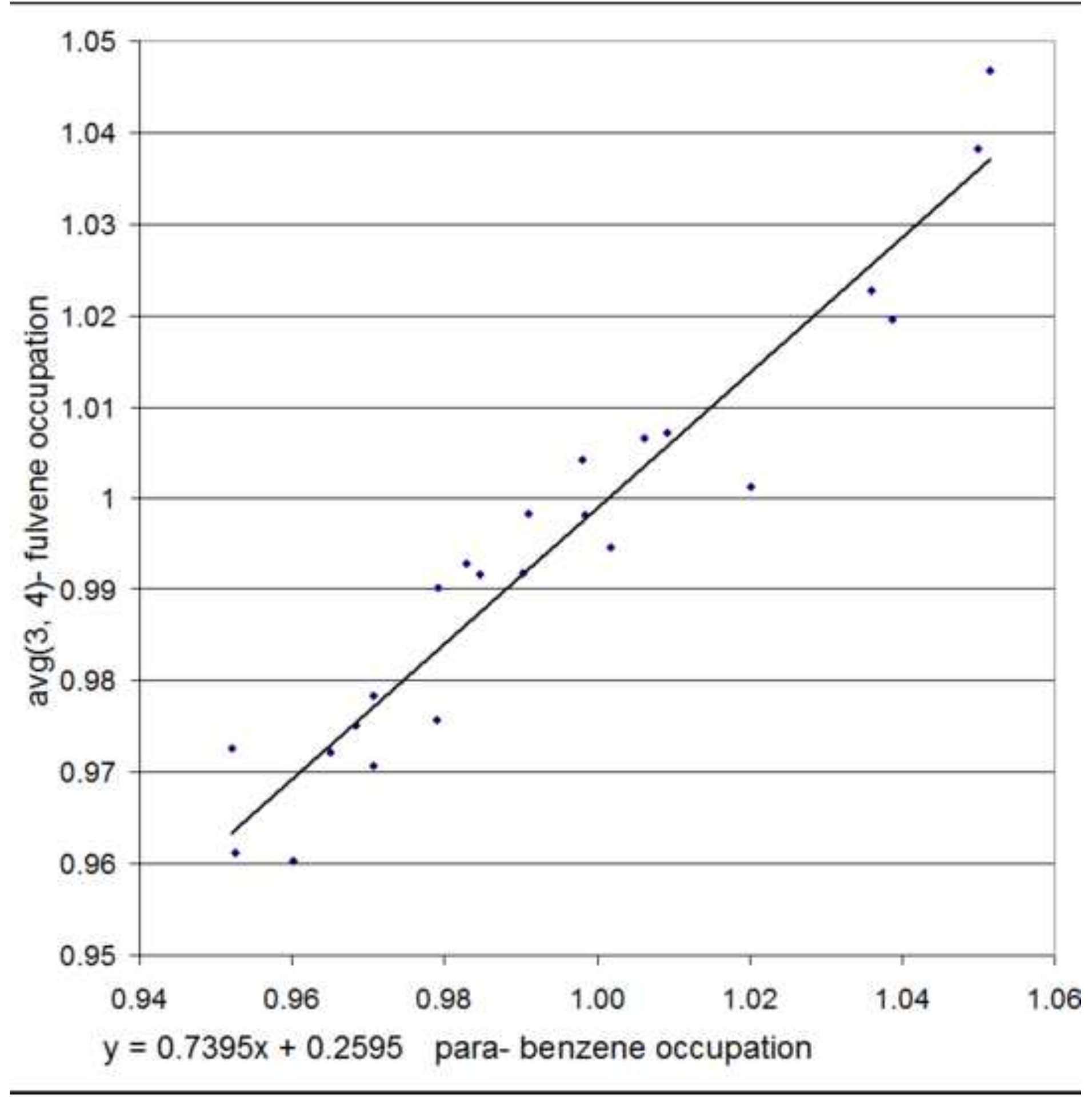


Figure 15
Click here to download high resolution image

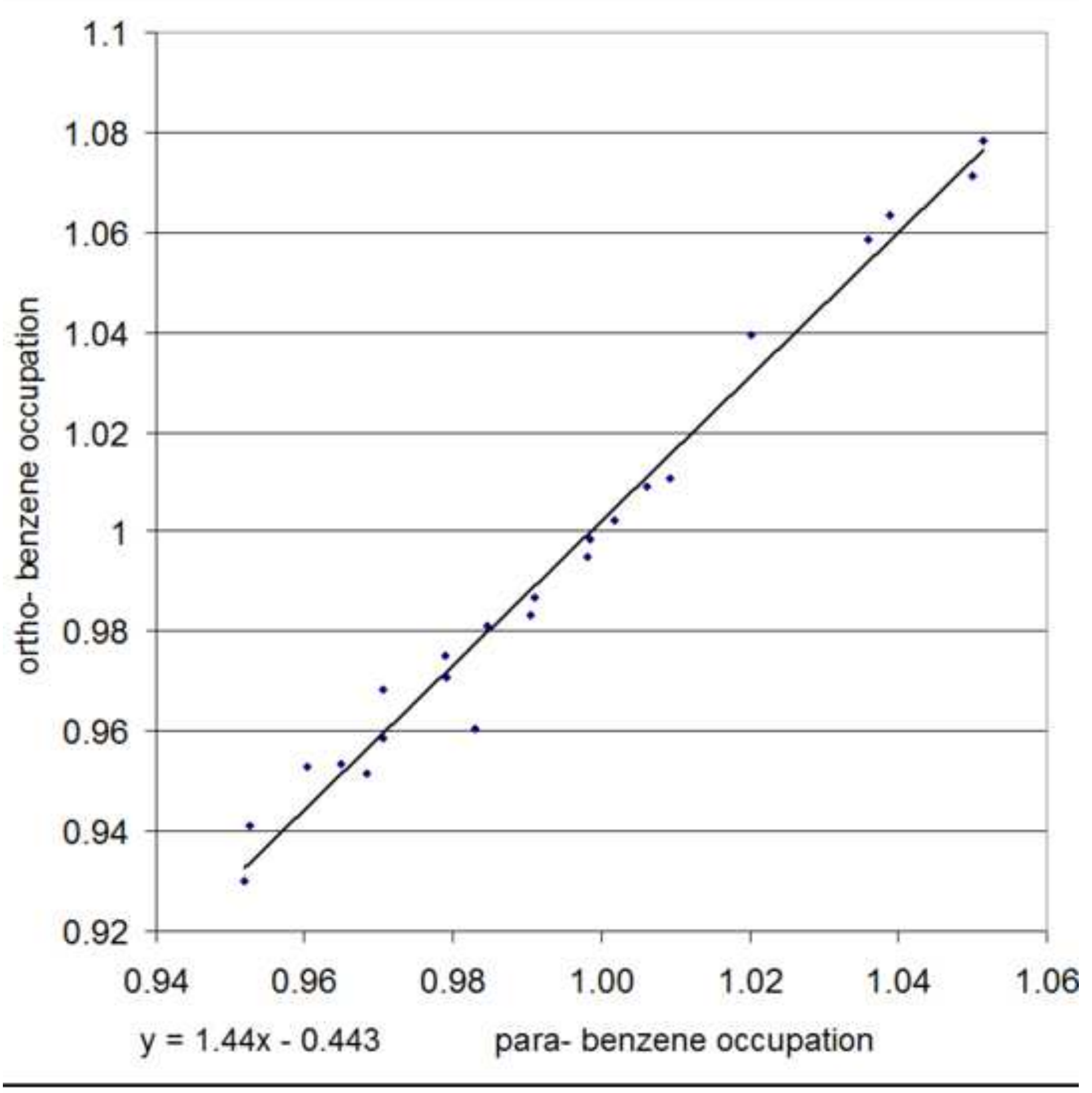


Figure 16
Click here to download high resolution image

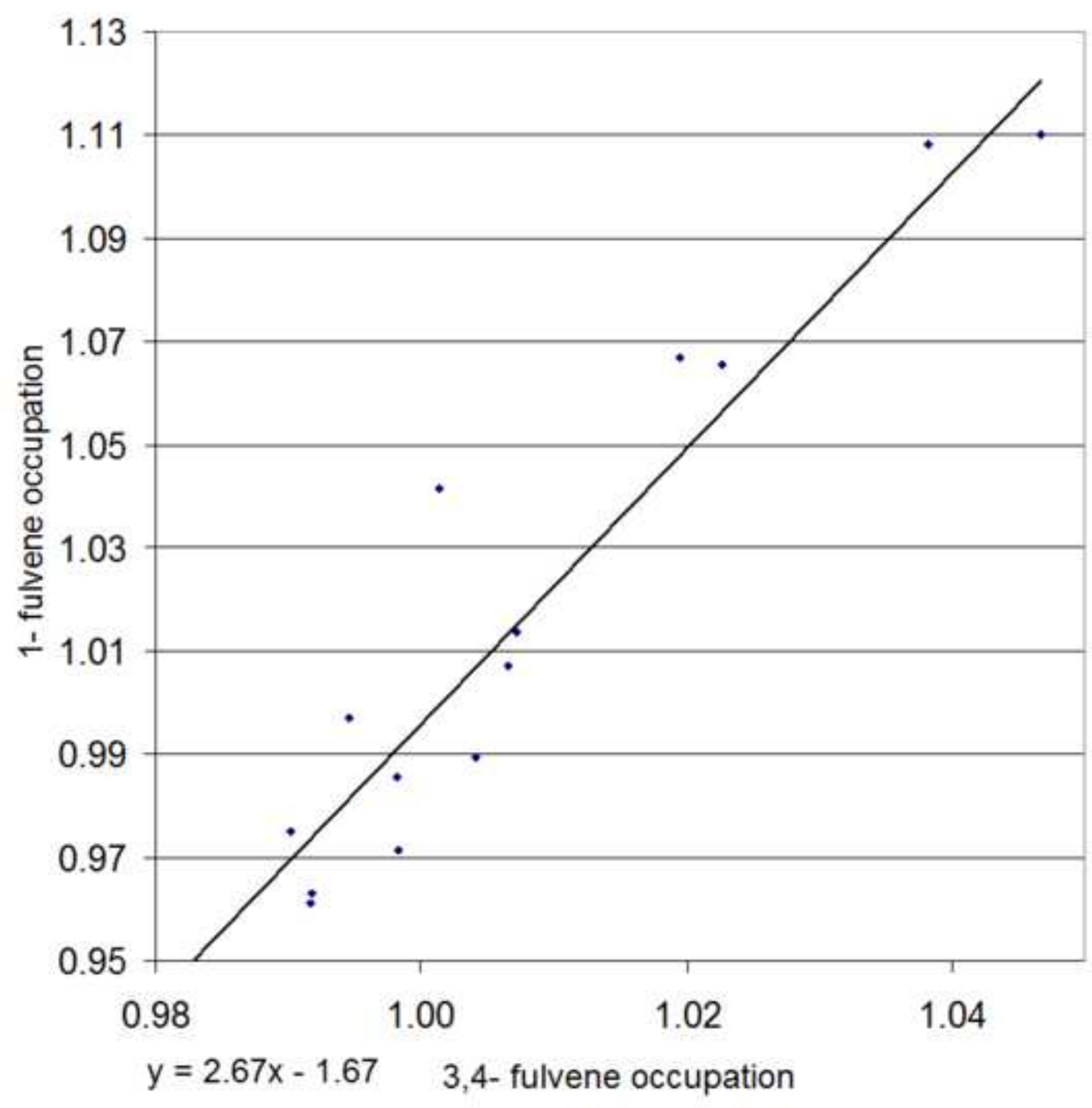


Figure 17
Click here to download high resolution image

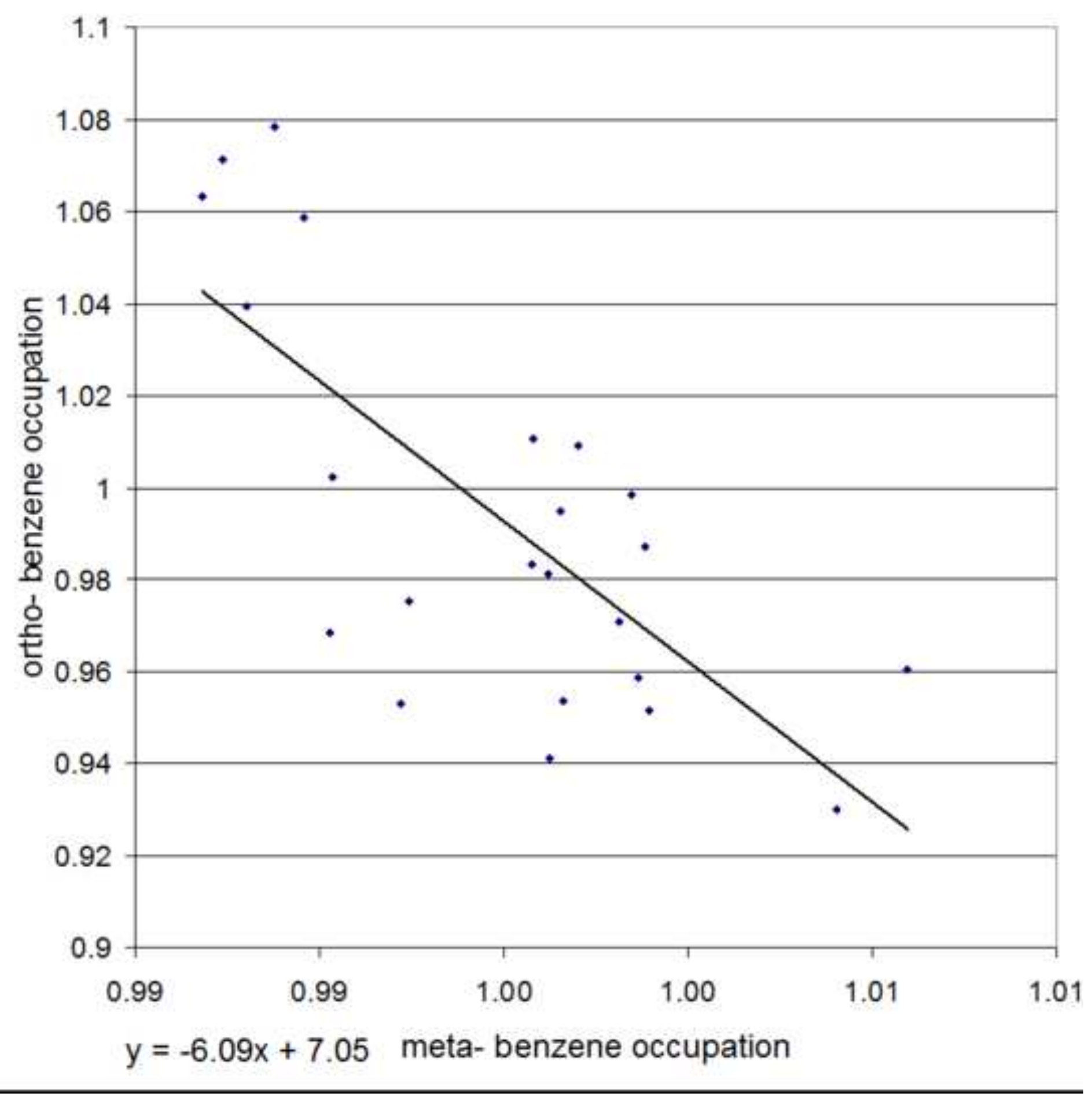


Click here to download high resolution image

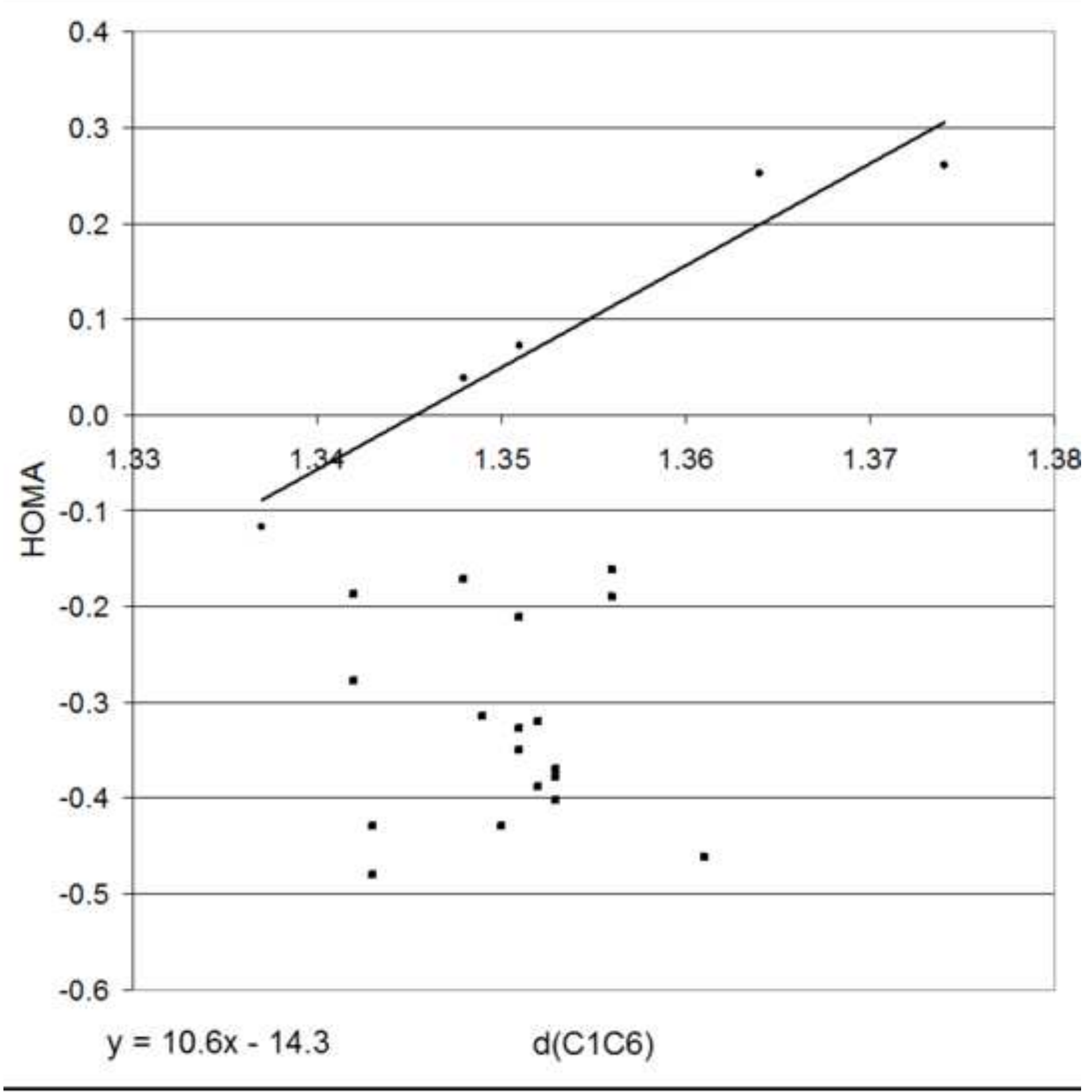

